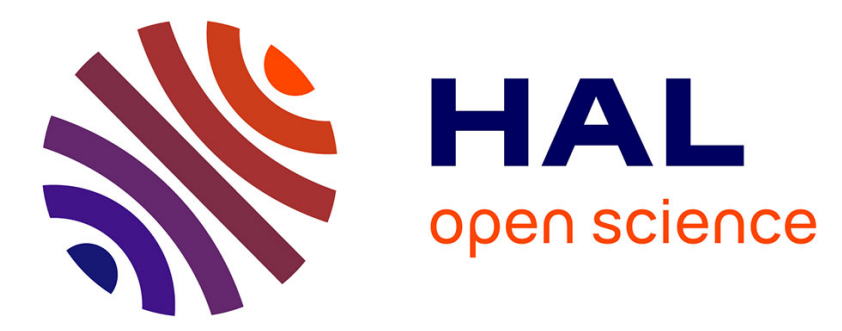

\title{
Molecular Dynamics simulations of clusters and thin film growth in the context of plasma sputtering deposition
}

Lu Xie, Pascal Brault, Jean-Marc Bauchire, Anne-Lise Thomann, Larbi Bedra

\section{To cite this version:}

Lu Xie, Pascal Brault, Jean-Marc Bauchire, Anne-Lise Thomann, Larbi Bedra. Molecular Dynamics simulations of clusters and thin film growth in the context of plasma sputtering deposition. Journal of Physics D: Applied Physics, 2014, 47, 224004 (17pp). hal-00955501

\section{HAL Id: hal-00955501 \\ https://hal.science/hal-00955501}

Submitted on 4 Mar 2014

HAL is a multi-disciplinary open access archive for the deposit and dissemination of scientific research documents, whether they are published or not. The documents may come from teaching and research institutions in France or abroad, or from public or private research centers.
L'archive ouverte pluridisciplinaire HAL, est destinée au dépôt et à la diffusion de documents scientifiques de niveau recherche, publiés ou non, émanant des établissements d'enseignement et de recherche français ou étrangers, des laboratoires publics ou privés. 


\title{
Molecular Dynamics simulations of clusters and thin film growth in the context of plasma sputtering deposition
}

(Running head: Cluster and thin film growth by MD simulations)

\author{
Lu Xie, Pascal Brault, Jean-Marc Bauchire, Anne-Lise Thomann, Larbi Bedra \\ GREMI UMR7344 CNRS - Université d'Orléans BP 6744 ORLEANS Cedex 2, \\ France \\ E-mail: Pascal.Brault@univ-orleans.fr
}

\begin{abstract}
Carrying out molecular Dynamics simulations is a relevant way for understanding growth phenomena at the atomic scale. Initial conditions are defined for reproducing deposition conditions of plasma sputtering experiments. Two case studies are developed for highlighting the implementation of molecular dynamics simulations in the context of plasma sputtering deposition: $\mathrm{Zr}_{\mathrm{x}} \mathrm{Cu}_{1-\mathrm{x}}$ metallic glass and $\mathrm{AlCoCrCuFeNi}$ high entropy alloy thin films deposited onto silicon. Effects of depositing atom kinetic energies and atomic composition are studied in order to predict evolution of morphologies and atomic structure of MD grown thin films. Experimental and simulated X-ray diffraction patterns are compared.
\end{abstract}

PACS: 81.15.Aa, 81.15.Cd, 68.55.J-, 02.70.Ns

Submitted to: Journal of Physics D: Applied Physics 


\section{Introduction}

Plasma sputtering technology is widely used both in research and in industry (Mattox 1989; Safi 2000; Kelly 2000; Musil 2005). Nevertheless, this fairly simple technology is continuously being improved (Helmersson, 2006; Alami, 2009; Sakarinos, 2010). A first interest of magnetron sputtering is to build coatings with improved or complementary properties compared to the pristine bulk materials. Essentially, thin film properties are related on composition and microstructures, which in turn depend on the deposition conditions and thus on sputtering plasma properties. A second specific property of plasma sputtering and thus more specifically magnetron sputtering, is it acts as an atom source, able to interact with an inert and/or reactive buffer gas, which is contributing to the plasma ignition and properties. Such a source is thus providing a sputtered vapour (more or less directed) with well defined composition, kinetic energy and angle distributions. Such "initial conditions" determine the building of the coatings, for which a special initial stage is the growth of supported clusters which may have interests in themselves. Studying plasma sputter growth of supported clusters and thin films remains a challenging task for understanding current properties (film morphology, use properties) and predicting new properties (Safi, 2000; Kelly, 2000; Musil 2005; Brault 2011). Due to the atomic nature of this deposition process, an insight of the growth processes at the atomic scale is thus of paramount importance. Precisely, molecular Dynamics is a simulation technique that is well suited for describing materials at the atomic scale (Alder, 1957, 1958, 1959; Allen, 1987; Haile 1992; Rapaport 1995; Frenkel 2001) and thus well suited for predicting clusters and thin film compositions and morphologies, as, for example issued from plasma deposition and growth experiments. So, numerous approaches have been proposed for describing plasma-surface phenomena (Graves 2001, 2009; Wadley, 2001; Bogaerts 2009, 2010, 2012; Brault 2011). Focus on plasma sputter growth using MD is intended for illustrating the power of MD and the capability of predicting morphology, structure and composition in agreement with experimental results (Georgieva, 2010, 2011; Xie 2013a, 2013b). In the next section, MD simulations are presented in the context of plasma sputter deposition, with emphasis on initial conditions. This will be followed by two original case studies which are highlighting the MD predictive capabilities for 
complex far from equilibrium systems: $\mathrm{Zr}_{\mathrm{x}} \mathrm{Cu}_{1-\mathrm{x}}$ metallic glass (MG) and $\mathrm{AlCoCrCuFeNi}$ high entropy alloy (HEA) thin films deposition and growth onto silicon (100) substrate. Effects of depositing atom kinetic energies and atomic composition will be studied in order to correlate with morphologies and atomic structure.

\section{Implementing MD simulations in the context of plasma sputtering deposition.}

\subsection{Classical molecular dynamics}

Classical molecular dynamics (MD) is a method intended to numerically solve the Newton equations of motion for a given system of particles, for which the interactions are governed by a model describing the forces between these particles. An advantage of molecular dynamics simulations is that systems can be studied with an atomic resolution at short time- and length-scales, down to femtoseconds and angstroms up to nanoseconds, sometimes to microseconds and a few hundred nanometers (Hansen, 2000). A very striking advantage in MD simulations is that no assumption is made about the mechanisms operating in the system. Molecular dynamics simulations consist in tracking the solutions of the classical equations of motion, written as:

$$
\vec{F}_{i}=m_{i} \vec{a}_{i}=m_{i} \frac{d \vec{v}_{i}}{d t}=m_{i} \frac{d^{2} \vec{r}_{i}}{d t^{2}}
$$

Where $m_{i}, \vec{r}_{i}, \vec{v}_{i}$ and $\vec{a}_{i}$ are the mass, position, velocity and acceleration of atom $i$ in a defined coordinate system, respectively. The force $\boldsymbol{F}_{i}$ acting on each atom $i$ accelerates the particle $i$, which in turn leads to a new position, velocity, and acceleration. Forces are derived as the negative gradients of the potential energy (interaction potential) $U$ with respect to atomic positions:

$$
\overrightarrow{\mathrm{F}}_{\mathrm{i}}=-\vec{\nabla}_{\mathrm{ri}} \mathrm{U}\left(\overrightarrow{\mathrm{r}}_{1}, \overrightarrow{\mathrm{r}}_{2}, \overrightarrow{\mathrm{r}}_{3}, \cdots, \overrightarrow{\mathrm{r}}_{\mathrm{N}}\right)
$$

The potential energy, can be obtained using either empirical potential energy expressions, semiempirical methods, or ab-initio approaches. In MD simulations, the calculations of the potential energy and force are the most computer time consuming parts. Once the initial conditions and interaction potential are defined, Equation (1) and (2) can be integrated to follow the time evolution of the atoms in response to the applied forces. The trajectory of all atoms can be thus obtained as solutions of 
Equation (2), in the form of positions and velocities of all the atoms at each time step. The velocity Verlet algorithm (Swope, 1982) is used for integrating Newton equations. For maintaining the substrate at the desired temperature $\left(\mathrm{T}_{\mathrm{s}}=300 \mathrm{~K}\right.$ in all simulations here) a Berendsen thermostat (Berendsen, 1984), is applied for a specified duration: the thermal relaxation time. Typical thermal relaxation times range from 0.1 to a 50 ps (Hou, 2000) per impact on the surface.

\subsection{Interaction potentials}

In classical MD simulations, the forces between atoms in the system are derived from a potential energy function; this functional form is often based on a quantum mechanical treatment of the system. The more fundamental quantum mechanical treatment is simplified, by the use of various approximations, the values of which are taken, either from first principle calculations, or from fits of the model to experimental data.

In the present work, Lennard-Jones potential are used to describe the interactions of the $\mathrm{Si}-(\mathrm{ZrCu})$ and the Si-(AlCoCrCuFeNi) systems (Zhang, 2002; Zhen, 1983; Graves, 2009). While pair potential parameters for the corresponding compound materials are not directly available, the Lorenz-Berthelot mixing rule is used. (Allen, 1987; Graves, 2009). More generally, for any kind of potential we can use, in a first approximation, the following general rules can be established: for length terms we consider arithmetic averaging and for energy terms, geometric averaging. One could guess that more precisely defined potentials were available, which is not the case for all of these metal - silicon substrate interactions. Extracting «true » potentials from ab-initio simulations is out of the scope of this article. Moreover successful comparison with experiments (Xie, 2013a, 2013b) allows using this metal substrate interaction potential for understanding effects of incoming atom kinetic energy and composition on morphology and structure of grown thin films.

Metal atom interactions can be well described by the so-called embedded atom model (EAM) (Foiles, 2012; Maisuradze, 2003). Such a potential, first introduced by Daw, Baskes and Foiles (Daw, 1983; Daw, 1984; Daw 1993; Foiles, 1985; Foiles, 1986), is non-pairwise in the sense that it is based on concepts coming from density functional theory which stipulates, in general that the energy of a solid is a unique function of electron density. The embedded-atom method uses the concept of electron 
(charge) density to describe metallic bonding. Essentially, each atom contributes through a spherical, exponentially-decaying field of electron charge, centred at its nucleus, to the overall charge density of a system. Binding of atoms is modelled as embedding these atoms in this "pool" of charge, where the energy gained by embedding an atom at location $r$ is some function of local density.The EAM parameters of $\mathrm{Al}, \mathrm{Co}, \mathrm{Cr}, \mathrm{Cu}, \mathrm{Fe}, \mathrm{Ni}, \mathrm{Zr}$ are given by Zhou et al (Zhou, 2001, 2004) and Lin et al (Lin, 2008).

Silicon substrate is described using Tersoff semi-empirical three-body potential (Tersoff 1988a, 1988b, 1989). This potential has been successfully used to investigate the structural, thermal vibration and surface properties of Si.

The EAM and Tersoff parameters are also implemented in the MD LAMMPS software (Plimpton, 1995, 2012).

There exist many other semi-empirical analytical potentials. Also suited to metals are tight binding potential (Rosato,1989; Sutton, 1990; Cleri, 1993; Treglia, 1999; Goyhenex, 2001, ). For covalent systems, reactive empirical bond order potentials - REBO and Adaptive Intermolecular REBO (Brenner, 1990, 2000; Stuart, 2000; Ni 2002; Nikitin 2005), are now widely used. A new reactive semi empirical ReaxFF potential is growingly attracting attention (van Duin, 2001; Nielson, 2005; Neyts, 2012).

\subsection{Initial conditions for releasing sputtered atoms.}

Plasma sputtering deposition consists in producing an atom source sputtered from biased solid targets by the created plasma ions, typically argon. The sputtered atoms (or molecules, clusters) will lose energy through collisions with the gas phase along the pathway to the substrate. We use a simple model of particle slowing down along straight-line trajectories, subject to a continuous energy loss process, which allows calculating the energy distributions of the particle flux as a function of the distance to the source. The mean kinetic energy of sputtered atoms is calculated according to the modification of Thompson formula, as the sputtered atoms are travelling through a gaseous medium (Meyer, 1981): 


$$
\begin{gathered}
\mathrm{f}(\mathrm{E}) \propto \frac{1-\left(\frac{\mathrm{E}_{\mathrm{coh}}+\mathrm{E}}{\gamma \mathrm{E}_{\mathrm{Ar}^{+}}}\right)^{\frac{1}{2}}}{\mathrm{E}^{2}\left(1+\frac{\mathrm{E}_{\mathrm{coh}}}{\mathrm{E}}\right)^{3}} \\
\mathrm{E}_{\mathrm{F}}=\left(\mathrm{E}-\mathrm{k}_{\mathrm{B}} \mathrm{T}_{\mathrm{g}}\right) \exp \left[\mathrm{n} \ln \left(\mathrm{E}_{\mathrm{f}} / \mathrm{E}_{\mathrm{i}}\right)\right]+\mathrm{k}_{\mathrm{B}} \mathrm{T}_{\mathrm{g}}
\end{gathered}
$$

$E_{f} / E_{i}=1-\gamma / 2$ is the ratio of energies after and before a collision, (Gras-Marti, 1983) with $\gamma=4 \frac{m_{g} m_{s}}{\left(m_{g}+m_{s}\right)^{2}}$ where $m_{g}$ and $m_{s}$ stand for plasma forming atom (argon here) and sputtered atom masses, respectively, and $n=d p \tau / k_{B} T_{g}$. E is the energy of the sputtered particles as they leave the target, $\mathrm{T}_{\mathrm{g}}$ is the sputtering gas temperature, $\mathrm{n}$ is the number of collisions that take place in the gas, $\mathrm{d}$ is the travelled distance, $\mathrm{p}$ is the sputtering gas pressure, and $\tau$ is the collision cross section assuming hard core interactions. To calculate the energy loss $\left(\mathrm{E}_{\mathrm{f}}\right)$ of sputtered atoms with the gas atoms, a Maxwell-Boltzmann (MB) distribution at $\mathrm{T}_{\mathrm{g}}$ is fixed for the gas (in our conditions $\mathrm{T}_{\mathrm{g}}=300 \mathrm{~K}, \mathrm{Eg}=$ $\mathrm{k}_{\mathrm{B}} \mathrm{T}_{\mathrm{g}}$ ). Because we search for the complete energy distribution of sputtered atoms, for each $\mathrm{E}_{\mathrm{g}}$ in the MB gas distribution, the energy loss is calculated for a fixed value of the kinetic energy $\mathrm{E}$ of a sputtered atom. This is repeated for each $\mathrm{E}$ in the Thompson distribution and weighted by the collision probability, which is simply the convolution of $\mathrm{f}(\mathrm{E})$ and the MB distribution at $\mathrm{T}_{\mathrm{g}}$. (Meyer, 1981). So, initial velocities or equivalently kinetic energies can be obtained from such a distribution using a rejection method (Press 1992). The velocities of the sputtered atoms can also be sampled from a Maxwell-Gaussian distribution with a mean kinetic energy corresponding to the energy loss calculated with Equation 4 with randomly selected incident angles. Finally Monte-Carlo solvers as SIMTRA (van Aeken, 2008, Depla, 2012) are able to calculate the energy and angle distribution function in three dimensions in the real plasma sputtering system. When the distribution function is found, a rejection method can be used to sample the kinetic energies and incidence angles of the impinging particles on the substrate.

When initial velocities and incidence angle are known, initial positions in the horizontal plane are randomly sampled in uniform distribution at a vertical position a bit greater than the atom - surface and atom-atom cut-off distances. The initial vertical position can be gradually changed as the film is 
growing for preventing section of position inside the film. For mimicking deposition the atoms should be released to the surface one after each other. The effect of argon ions is neglected in the present simulations, so no argon ions are released to the surface during deposition.

\subsection{Limitations and capabilities of MD deposition studies.}

The time interval between each released atom should be chosen greater than the energy relaxation of the substrate after the collision, which ranges from 1 to few tens of picoseconds (Hou, 2000; Brault, 2012). It is necessary to be aware that atom fluxes in MD are unphysically large when comparing with experiment. When considering MD simulations, sputtered atoms are released here every $\tau=2$ ps on a

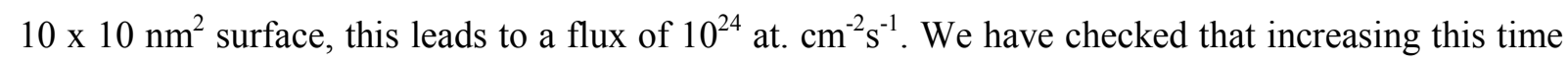
does not change the results. This should be compared to a typical flux encountered in sputtering deposition: say, $10^{15}$ at. $\mathrm{cm}^{-2} \mathrm{~s}^{-1}$ (around $1 \mu \mathrm{m} \cdot \mathrm{h}^{-1}$ ). The first and important consequence is there is no possibility for predicting a deposition rate. Nevertheless, when recalling that excess energy is correctly described using an appropriate thermostat, other information as sticking coefficient, structure, and morphology are reachable. Moreover information as radial density functions (RDF) and simulated xray diffraction (XRD) patterns can be readily compared to experiments (Hansen, 2000; Xie, 2013a, 2013b). The second main limitation is the possible long time diffusion occurring in growth process on surface. Some strategies have recently been successfully carried out including Monte-Carlo procedure coupled to MD simulations (Blackwell, 2012; Neyts, 2013). Such investigations are out of the scope of this article, because in the present studies, individual atomic motions are much localised for HEA and metallic glasses. Indeed, we have the chance that the atom size difference acts for preventing large diffusion leading to the (near)-amorphous phase. The used potentials have the effect of normally leading to crystalline phase for individual atoms (see $\mathrm{ZrCu}$ with large $\mathrm{Cu}$ of $\mathrm{Zr}$ content). Moreover in the present simulations, we have carried out simulation on 100 and $17 \AA$ substrate widths without any significant differences. We think this comes from the size difference between atoms. For atomsubstrate interaction, the cut-off length is always less than half the box size: this prevents the size effects when applying periodic boundary conditions. More precise description of the metal-silicon will require ab-initio determination of the interaction potentials. 


\section{Case study 1: $\mathrm{Zr}_{\mathrm{x}} \mathrm{Cu} \mathbf{u}_{100-\mathrm{x}}(10 \leq \mathrm{x} \leq 90)$ thin films deposited on a silicon (100) substrate: effect of the deposited atom kinetic energy}

Recently, there has been a huge interest in the atomic-level structure and structure-property relationship in metallic glasses (MGs). These materials have been studied for 40 years because of their promising properties belonging to both metals (electron, heat conductivity, ductility...) and glasses (hardness...) (Li, 2007; Masumoto, 1994). To stabilize an amorphous phase in metallic alloys, atomic diffusion must be prevented. This could be achieved by setting up with the chemical composition (mixing of elements with different atomic sizes) or by freezing a low ordered phase during the synthesis process (Kawamura, 1997). It has been shown that deposition of thin films by condensation onto cold substrates allows stabilizing low ordered structure in such systems.

As an example, $\mathrm{ZrCu}$ alloys have attracted interest in recent years, due to their bulk metallic glass properties (Cheng, 2011; Wang, 2004; Yu, 2006; Păduraru, 2007; Mei-Bo, 2004), and as amorphous alloy films for their mechanical (Xu, 2004; Musil, 2003; Das, 2005) and superconductivity properties (Karpe, 1996). Dudonis et al. (Dudonis, 1996) prepared thin films with $\mathrm{Zr}$ composition in the range of ( $5 \leq \mathrm{x} \leq 95)$ by using high working power $(490 \mathrm{~W}$ and $1380 \mathrm{~W}$ on $\mathrm{Cu}$ and $\mathrm{Zr}$ targets, respectively) during magnetron sputter deposition.

Numerous theoretical studies have also been conducted on $\mathrm{ZrCu}$ systems. Sha et al employed atomistic methods (among them MD) for studying $\mathrm{ZrCu}$ MGs forming conditions (Sha, 2010, 2012). Almyras et al investigated the microstructure of $\mathrm{Zr}_{35} \mathrm{Cu}_{65}$ and $\mathrm{Zr}_{65} \mathrm{Cu}_{35}$ MGs and found that these systems consist of small touching and/or interpenetrating icosahedral-like clusters which results in "supercluster" (SCs) satisfying the system composition (Almyras, 2010). They thus claimed that seeking the equilibrium configuration for interpenetrating icosaedron-like clusters allows the prediction of the MG microstructure. While bulk amorphous structure is known to be formed under specific synthesis conditions, the dynamics of growth of $\mathrm{ZrCu}$ amorphous thin film has not been so much studied using MD. A better understanding of thin film growth can be thus achieved via MD simulations. 
Mean kinetic energies are determined using Equations (3), (4) and the corresponding averaging procedure summarized in section 2.3. The aim is to reproduce the three different experimental situations summarized in Table 1, for which MD growth runs are simulated. This is intended for determining the role of both the composition and the deposited atom kinetic energy on the formation of the expected amorphous phase.

Table 1: The calculated mean kinetic energies of incoming $\mathrm{Zr}$ and $\mathrm{Cu}$ atoms corresponding to three different experimental conditions.

\begin{tabular}{|c|c|c|c|}
\hline $\begin{array}{c}\text { Sets of } \\
\text { simulations }\end{array}$ & $\mathrm{Zr}(\mathrm{eV})$ & $\mathrm{Cu}(\mathrm{eV})$ & Co rresponding magnetron sputtering experimental conditions \\
\hline 1 & 0.13 & 0.34 & $\mathrm{~d}_{\mathrm{T}-\mathrm{S}}=7 \mathrm{~cm}, \mathrm{P}=3 \mathrm{~Pa}, \begin{array}{c}\text { Target bias }(\mathrm{Zr})=460 \mathrm{~V}, \text { Target bias } \\
(\mathrm{Cu})=490 \mathrm{~V}\end{array}$ \\
\hline 2 & 7.65 & 6.67 & $\mathrm{~d}_{\mathrm{T}-\mathrm{S}}=9 \mathrm{~cm}, \mathrm{P}=0.25 \mathrm{~Pa}$, Target bias $=300 \mathrm{~V}$ \\
\hline 3 & 12.6 & 9.61 & $\mathrm{~d}_{\mathrm{T}-\mathrm{S}}=7 \mathrm{~cm}, \mathrm{P}=0.03 \mathrm{~Pa}$, Target bias $(\mathrm{Zr})=460 \mathrm{~V}$, Target bias \\
$(\mathrm{Cu})=490 \mathrm{~V}$
\end{tabular}

MD simulation was carried out in a three dimensional cell, which was periodic only along $\mathrm{x}$ and $\mathrm{y}$ directions. The dimensions of the Silicon $(100)$ substrate are $(25 \times 25 \times 10) \AA^{3}$. The first two bottom layers of the substrate are fixed, while the other layers are temperature - controlled layers using a Berendsen thermostat. The $\mathrm{Zr}$ and $\mathrm{Cu}$ atoms with the different ratios are randomly deposited on the substrate (one atom is released every $2 \mathrm{ps}$ ). The integration time-step is chosen to be $1 \mathrm{fs}$. The total number of released atoms is 10000 , leading to a total simulation time of $20 \mathrm{~ns}$. Each atom is placed in the vacuum slab at a random position from 5 to $7 \AA$ above the surface. $\mathrm{Zr}$ with composition $3<\mathrm{x}<95$ is selected if a generated random number $\xi$ is less than $\mathrm{x} / 100$, else $\mathrm{Cu}$ is chosen . The composition of the films is nearly the vapour composition and sticking coefficients for all compositions are close to $90 \%$. The initial velocities are randomly sampled in a Maxwell-Boltzmann distribution with the defined mean kinetic energy.

In the first set of simulations, the mean kinetic energies of incoming atoms are low: $\left\langle\mathrm{E}_{\mathrm{Zr}}>=0.13 \mathrm{eV}\right.$ 
and $\left\langle\mathrm{E}_{\mathrm{Cu}}\right\rangle=0.34 \mathrm{eV}$. Snapshots of the films deposited on the $\mathrm{Si}(100)$ are displayed in Figure 1. It is interesting to see that, as the $\mathrm{Zr}$ concentration increases, the morphology goes through three different stages: film - cluster - film. As we can see from figure $1, \mathrm{Zr}_{10} \mathrm{Cu}_{90}$ is deposited as a film with a thickness around $4 \mathrm{~nm}$. Then from $\mathrm{Zr}_{20} \mathrm{Cu}_{80}$ to $\mathrm{Zr}_{50} \mathrm{Cu}_{50}$, the deposited atoms grow as clusters with height ranging from $6.5 \mathrm{~nm} \sim 7.5 \mathrm{~nm}$. Finally, for $\mathrm{Zr}_{60} \mathrm{Cu}_{40}$ to $\mathrm{Zr}_{90} \mathrm{Cu}_{10}$, a film is formed with thickness ranging from $5 \mathrm{~nm} \sim 7.5 \mathrm{~nm}$.

\section{Zr10Cu90 (873/7854 at.) Zr20Cu80 (1786/7136 at.) Zr30Cu70 (2695/6320 at.)}
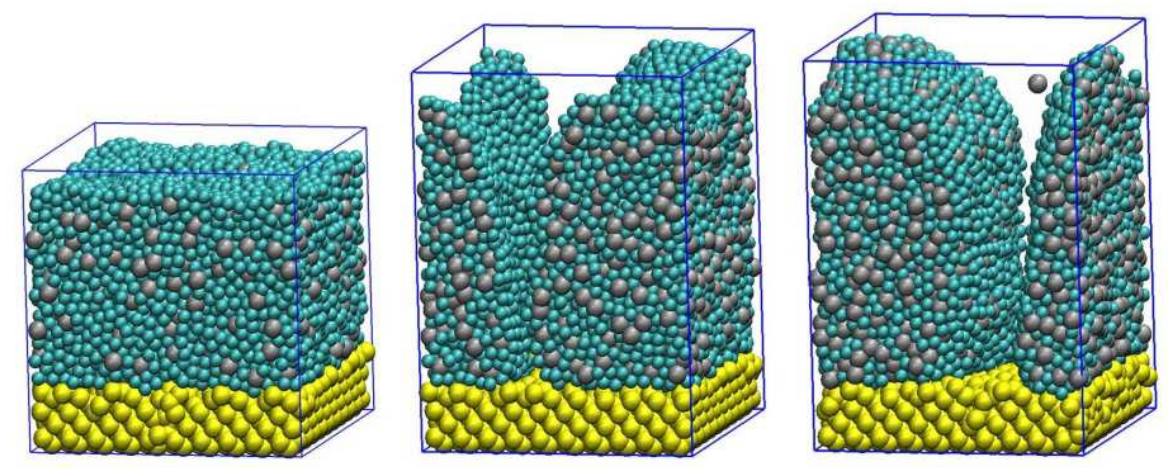

Zr40Cu60 (3573/5413 at.) Zr50Cu50 (4540/4506 at.) Zr60Cu40 (5398/3602 at.)
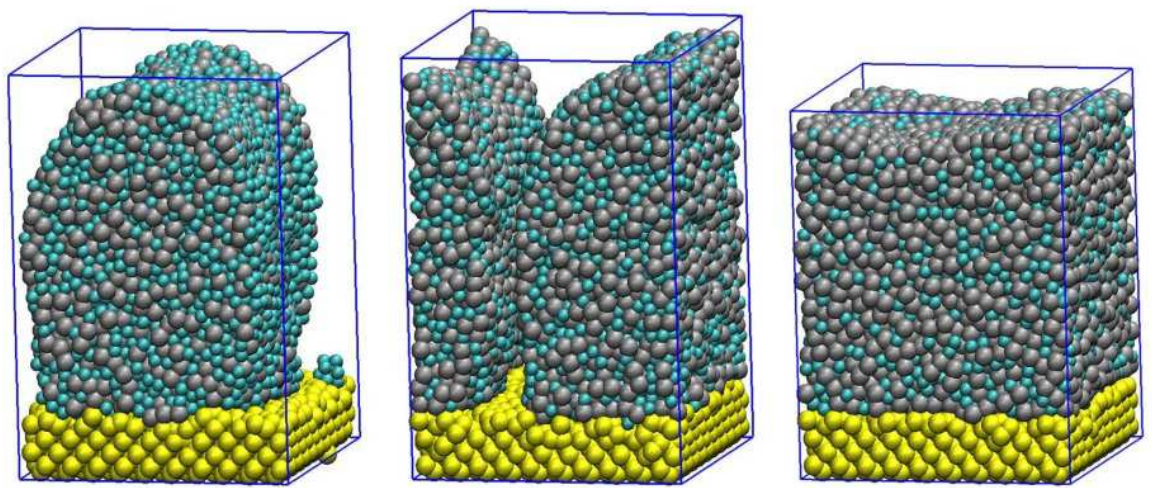

Zr70Cu30 (6138/2642 at.) Zr80Cu20 (7063/1751 at.) Zr9oCu10 (8212/908 at.)
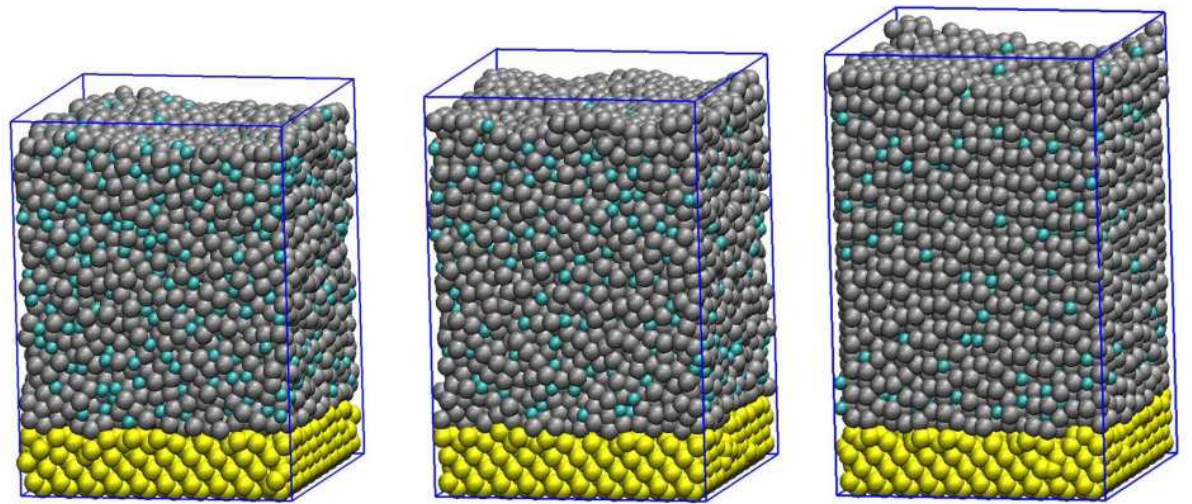

Figure 1: Snapshots of $\mathrm{Zr}-\mathrm{Cu}$ coatings deposited on $\mathrm{Si}(100)$ substrate at different ratios of $\mathrm{Zr}$ and $\mathrm{Cu}$ 
atoms (the numbers in brackets are the $\mathrm{Zr}$ and $\mathrm{Cu}$ atom numbers respectively, leading to sticking coefficient around 90\%). $\bullet \mathrm{Zr}, \bullet \mathrm{Cu}, \bullet$ Si. Mean kinetic energies are $\left\langle\mathrm{E}_{\mathrm{Zr}}\right\rangle=0.13 \mathrm{eV}$ and $\left\langle\mathrm{E}_{\mathrm{Cu}}>=\right.$ $0.34 \mathrm{eV}$

Figure 2 shows the total RDF of the all-all pair for these simulation sets. For the $\mathrm{Zr}_{90} \mathrm{Cu}_{10}$ deposit RDF, four peaks arise up in this plot showing the well crystallized structure, which can also be clearly seen in Figure 1. From $\mathrm{Zr}_{10} \mathrm{Cu}_{90}$ to $\mathrm{Zr}_{80} \mathrm{Cu}_{20}$, the first peak shifts towards larger radial distance as the concentration of $\mathrm{Zr}$ increases from $10 \%$ to $90 \%$, because the first neighbour distance of $\mathrm{Zr}(3.23 \AA)$ is larger than that of $\mathrm{Cu}(2.55 \AA)$. With the increase of $\mathrm{Zr}$ concentration, the structure of the system is changed from $\mathrm{Cu}$ predominant film to $\mathrm{Zr}$ predominant film presenting an amorphous structure.

Meanwhile, in the RDFs of $\mathrm{Zr}_{10} \mathrm{Cu}_{90}$ to $\mathrm{Zr}_{80} \mathrm{Cu}_{20}$, the $1^{\text {st }}$ peak broadens and splits comparing with $\mathrm{Zr}_{90} \mathrm{Cu}_{10}$ which has outstanding peaks typical of a crystalline structure. The amorphous nature of the alloys in the range 10 to $80 \%$ is clearly shown on the snapshots presented in Figure 1 .

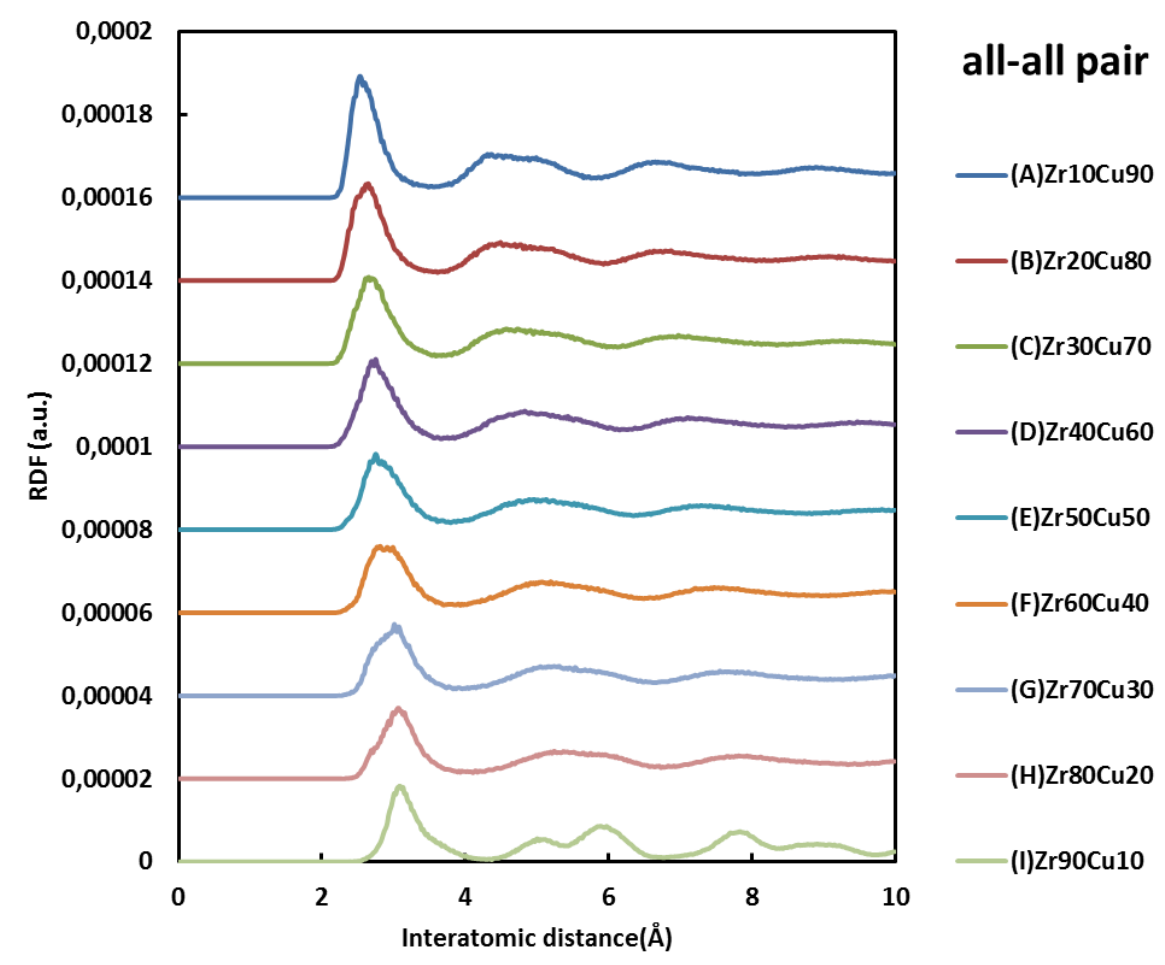

Figure 2: Total RDFs for $\mathrm{Zr}_{\mathrm{x}} \mathrm{Cu}_{100-\mathrm{x}}$ alloys, individual curves corresponding to different alloy compositions are displaced vertically for clarity.

Figure 3 shows the intensity and position of the XRD $\theta-2 \theta$ peaks as a function of the $\mathrm{Zr}$ metal content. 
Again at the $\mathrm{Zr}$ concentration of $90 \%, \mathrm{Zr}_{\mathrm{x}} \mathrm{Cu}_{100-\mathrm{x}}$ films are crystalline which agrees with snapshot in figure 1 . As the $\mathrm{Zr}$ concentration increases from $10 \%$ to $80 \%$, a shift of the peaks towards small angles (table 2) is observed. At the same time, all of these patterns consist of broader peaks, indicating a low ordered structure. In $\mathrm{Zr}_{90} \mathrm{Cu}_{10}, \mathrm{Cu}$ atom with the small diameter can enter the gap between the $\mathrm{Zr}$ atoms, which has no or only little effect on the overall structure. While for $\mathrm{Zr}_{10} \mathrm{Cu}_{90}$, even a small content of $\mathrm{Zr}$, due to a larger diameter, disturbs the crystalline structure of $\mathrm{Cu}$.

Table 2: Position of the main XRD peak for $\mathrm{ZrCu}$ alloy in the simulation Unit: $2 \theta\left(^{\circ}\right)$

\begin{tabular}{|c|c|c|c|c|c|}
\hline $\mathrm{Zr}-\mathrm{Cu}$ & $\mathrm{Zr}_{10} \mathrm{Cu}_{90}$ & $\mathrm{Zr}_{20} \mathrm{Cu}_{80}$ & $\mathrm{Zr}_{30} \mathrm{Cu}_{70}$ & $\mathrm{Zr}_{40} \mathrm{Cu}_{60}$ & $\mathrm{Zr}_{50} \mathrm{Cu}_{50}$ \\
\hline main peak & 42.45 & 41.6 & 40.5 & 39.7 & 38.65 \\
\hline $\mathrm{Zr}-\mathrm{Cu}$ & $\mathrm{Zr}_{60} \mathrm{Cu}_{40}$ & $\mathrm{Zr}_{70} \mathrm{Cu}_{30}$ & $\mathrm{Zr}_{80} \mathrm{Cu}_{20}$ & \multicolumn{2}{|c|}{$\mathrm{Zr}_{90} \mathrm{Cu}_{10}$} \\
\hline main peak & 37.8 & 37.0 & 36.25 & \multicolumn{2}{|c|}{35.7} \\
\hline
\end{tabular}

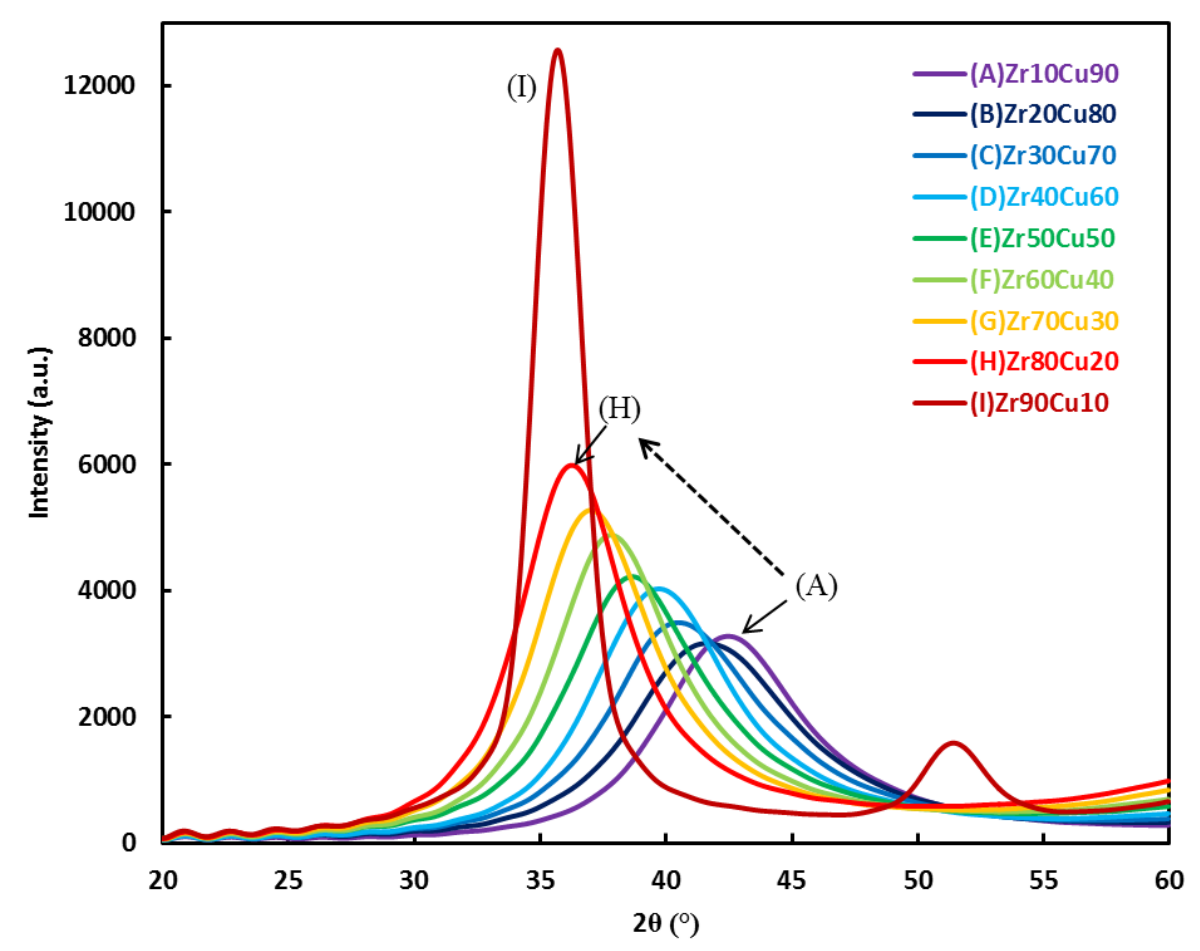

Figure 3: Calculated X-Ray intensity vs. $2 \theta$ of $\mathrm{Zr}_{\mathrm{x}} \mathrm{Cu}_{100-\mathrm{x}}$ film with different compositions. 
For a deeper insight in the film growth mechanism of $\mathrm{Zr}_{90} \mathrm{Cu}_{10}$, a snapshot at the lowest kinetic energies is shown in Figure 4. The black solid line underlines the crystal lattice mis-orientation. Clearly, the film exhibits two grains: one in orientation marked as " $\mathrm{A}$ " and the other in orientation marked as "B".

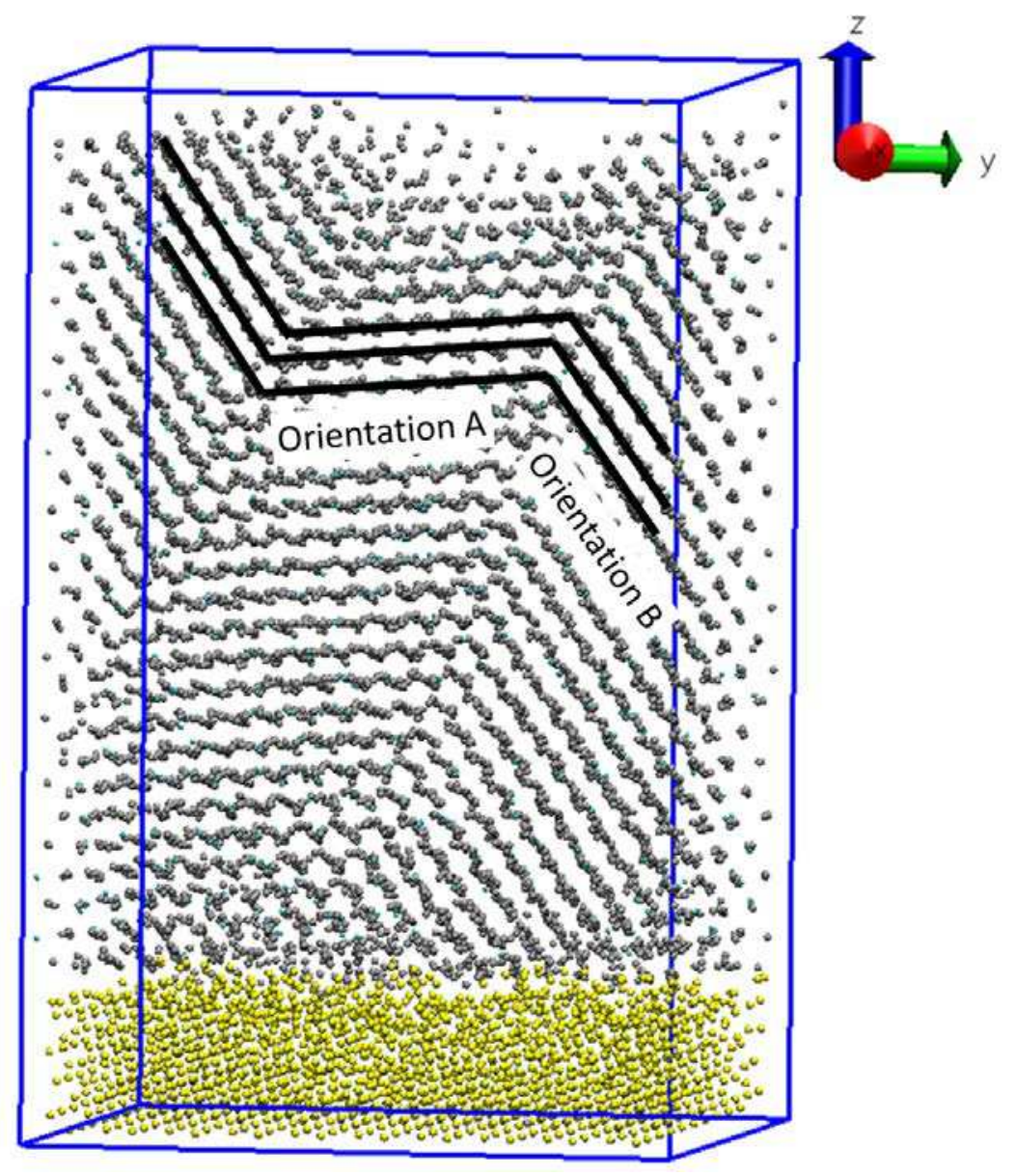

Figure 4: Snapshot of sputtered $\mathrm{Zr}_{90} \mathrm{Cu}_{10}$ with the lowest energies (set 1), blue outline show its original cell in MD simulation and solid line show the crystal lattice orientation. The atom size is reduced for highlighting the two grain structures.

At the beginning of the deposition process, the formed stable nuclei are crystalline with a random orientation distribution. As a result, the growth and coalescence of small clusters leads to their coarsening. In this simulation the energy of deposited atom is not high enough to overcome the diffusion activation energy and restructuration between clusters cannot occur. Therefore the boundary 
is immobile through all the film thickness. As the depositions goes on, the clusters have a similar growth rate but with different growing direction, as a result, two grains are formed with different lattice orientations.

For the condition 2 (medium-high energies, $<\mathrm{E}_{\mathrm{Zr}}>=7.65$ and $<\mathrm{E}_{\mathrm{Cu}}>=6.67 \mathrm{eV}$ ), the morphologies of films deposited on the $\mathrm{Si}(100)$ are displayed in Figure 5. To precisely study the appearance of the amorphous phase, the range of $\mathrm{Zr}$ composition is varied between 3 to $95 \%$. The films grew to approximately 4 to $9 \mathrm{~nm}$ when increasing $\mathrm{Zr}$ concentration.
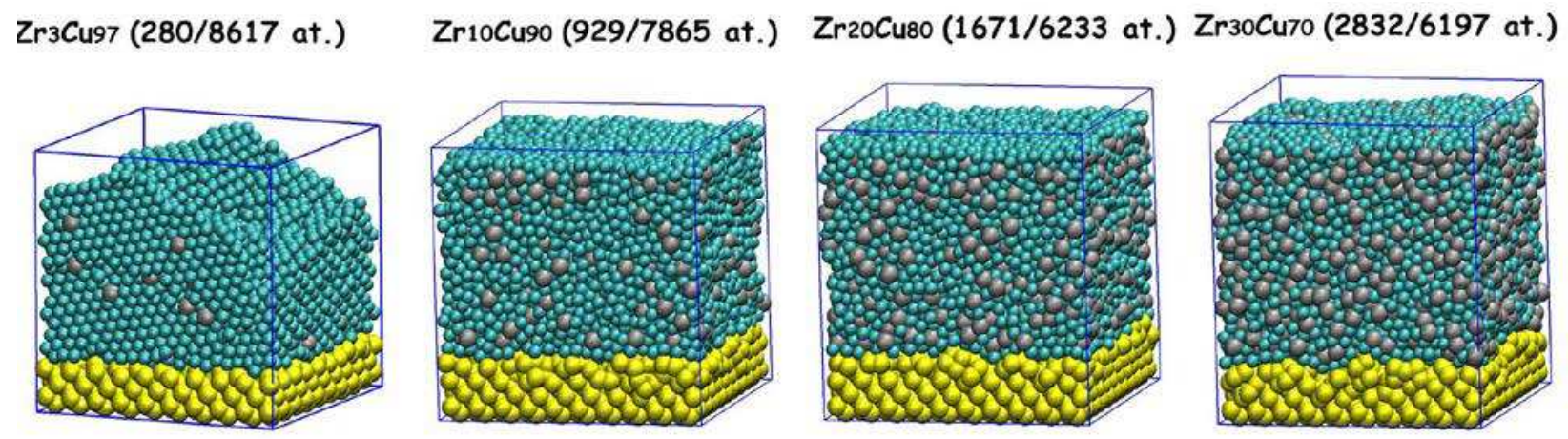

Zr40Cu60 (3757/5304 at.)
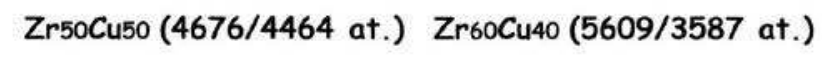

Zr70Cu30 (6507/2704 at.)
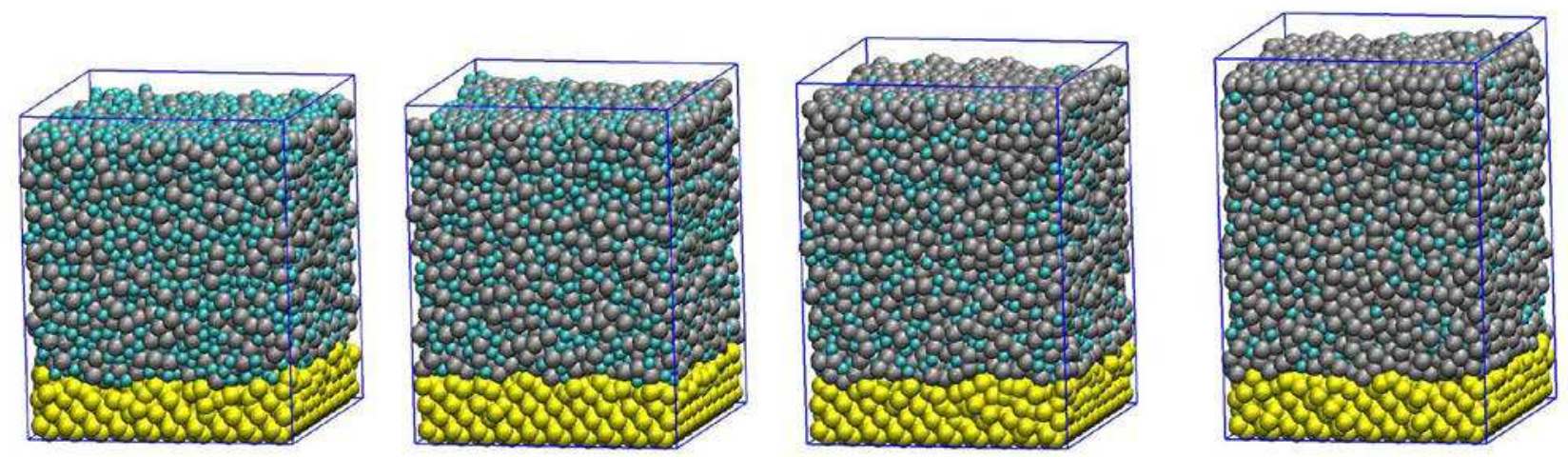

Zr80Cu20 (7485/1805 at.) Zr9oCu10 (8239/900 at.)

\section{Zr95Cu5 (8864/437 at.)}
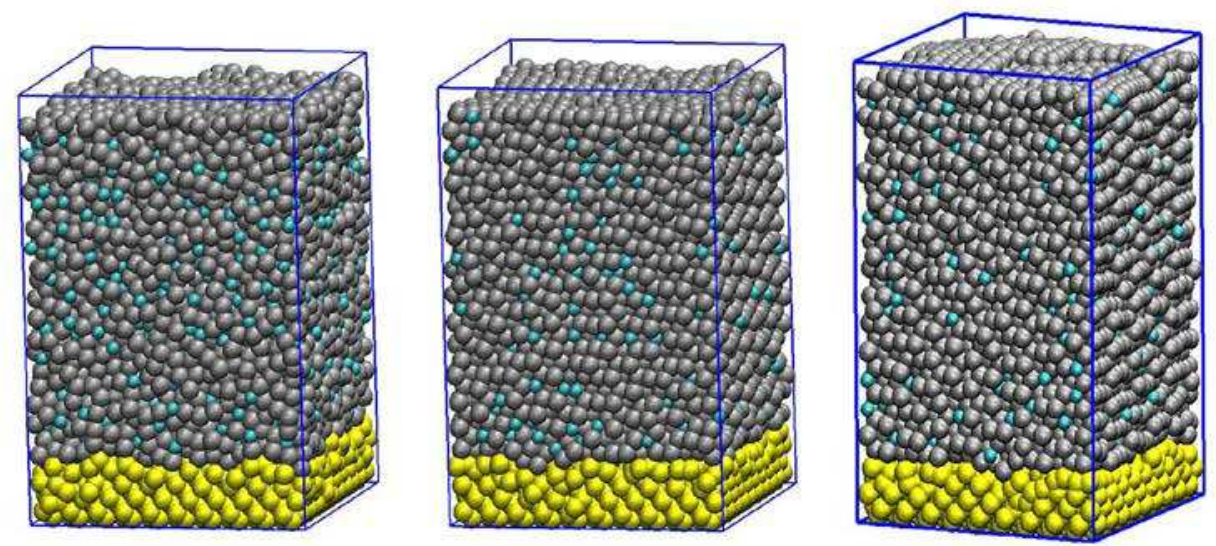

Figure 5: Snapshots of $\mathrm{Zr}-\mathrm{Cu}$ coatings deposited on $\mathrm{Si}(100)$ substrate at different $\mathrm{Zr} / \mathrm{Cu}$ ratios (the 
numbers in brackets are the $\mathrm{Zr}$ and $\mathrm{Cu}$ atom numbers respectively). $\bullet \mathrm{Zr}, \bullet \mathrm{Cu}, \bullet \mathrm{Si}$. Mean kinetic energies are $<\mathrm{E}_{\mathrm{Zr}}>=7.65$ and $<\mathrm{E}_{\mathrm{Cu}}>=6.67 \mathrm{eV}$

Based on these simulations, the total radial density functions (RDF) for $\mathrm{Zr}$ metal contents varying from $3 \%$ to $95 \%$ are presented in Figure 6. Meanwhile, in the RDFs of $\mathrm{Zr}_{10} \mathrm{Cu}_{90}$ to $\mathrm{Zr}_{80} \mathrm{Cu}_{20}$, the peak becomes broad and split as compared to $\mathrm{Zr}_{3} \mathrm{Cu}_{97}, \mathrm{Zr}_{90} \mathrm{Cu}_{10}$ and $\mathrm{Zr}_{95} \mathrm{Cu}_{5}$, which have outstanding peaks typical of a crystalline structure. The amorphous nature of the alloys in the range 10 to $80 \%$ is clearly shown on the snapshots presented in Figure 5.

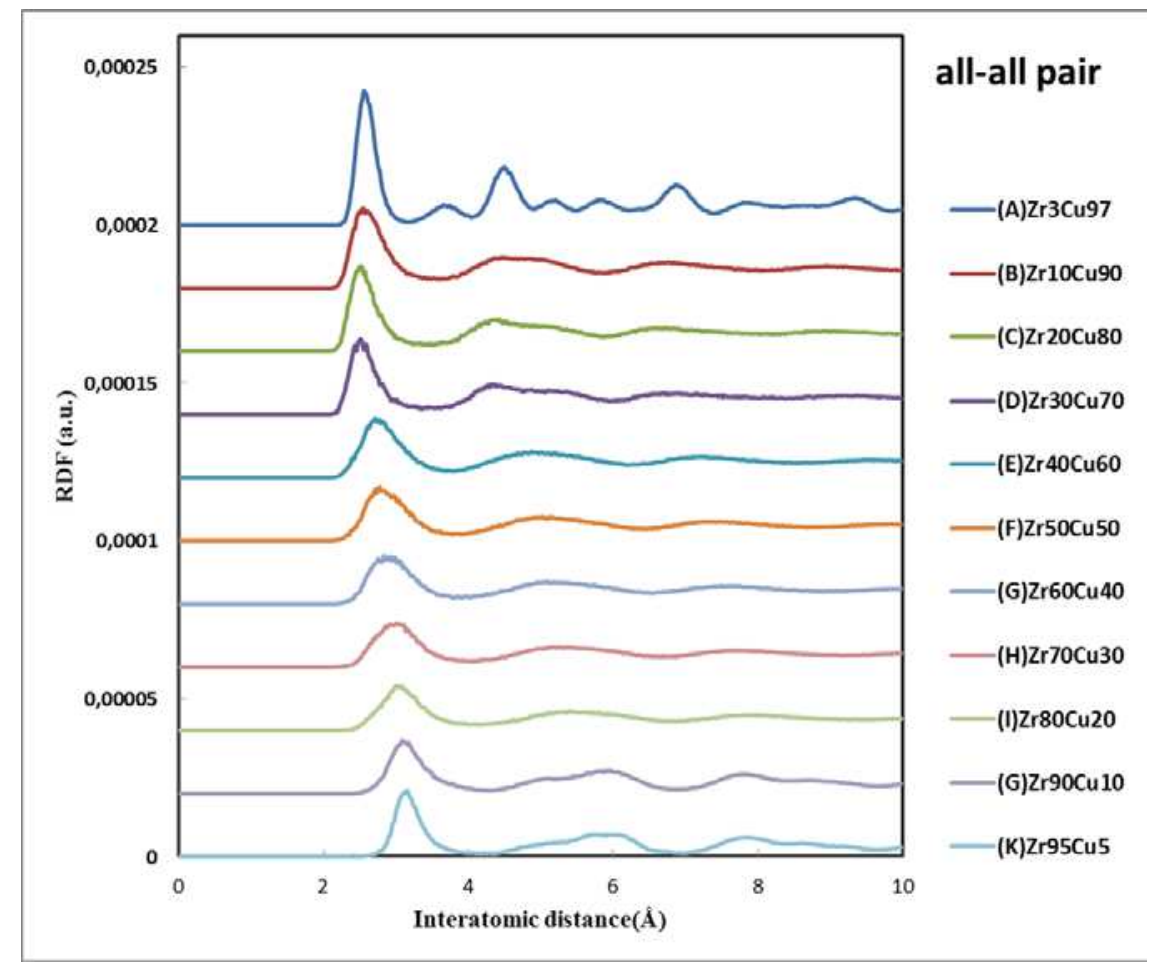

Figure 6: Total RDFs for amorphous $\mathrm{Zr}_{\mathrm{x}} \mathrm{Cu}_{100-\mathrm{x}}$ alloys, $3<\mathrm{x}<95$.

The calculated X-ray intensities vs. $2-\theta$ of $\mathrm{Zr}_{\mathrm{x}} \mathrm{Cu}_{100-\mathrm{x}}$ simulated films are shown in Figure 7 and peak positions in Table 3. At high concentrations of $\mathrm{Zr}$ or $\mathrm{Cu}$, i.e. for $\mathrm{Zr}_{3} \mathrm{Cu}_{97}, \mathrm{Zr}_{90} \mathrm{Cu}_{10}$ and $\mathrm{Zr}_{95} \mathrm{Cu}_{5}$, films show a crystalline XRD pattern which agrees with the present RDFs calculations reported in Figure 6. However, $\mathrm{Zr}_{10} \mathrm{Cu}_{90}$ can be considered as an exception to this. With the same concentration, $\mathrm{Zr}_{90} \mathrm{Cu}_{10}$ has a crystalline structure, but $\mathrm{Zr}_{10} \mathrm{Cu}_{90}$ is amorphous which is also clearly shown from the snapshots of the films presented in Figure 5. This is again because of the atom size difference between $\mathrm{Zr}$ and 
$\mathrm{Cu}$.

Table 3: Position of the main XRD peak for $\mathrm{ZrCu}$ alloy in the simulation (Unit: $2 \theta\left(^{\circ}\right)$ )

\begin{tabular}{|c|l|c|c|c|c|c|}
\hline $\mathrm{Zr}-\mathrm{Cu}$ & $\mathrm{Zr}_{3} \mathrm{Cu}_{97}$ & $\mathrm{Zr}_{10} \mathrm{Cu}_{90}$ & $\mathrm{Zr}_{20} \mathrm{Cu}_{80}$ & $\mathrm{Zr}_{30} \mathrm{Cu}_{70}$ & $\mathrm{Zr}_{40} \mathrm{Cu}_{60}$ & $\mathrm{Zr}_{50} \mathrm{Cu}_{50}$ \\
\hline main peak & 42.1 & 42.1 & 41.7 & 40.35 & 39.4 & 38.4 \\
\hline $\mathrm{Zr}-\mathrm{Cu}$ & $\mathrm{Zr}_{60} \mathrm{Cu}_{40}$ & $\mathrm{Zr}_{70} \mathrm{Cu}_{30}$ & $\mathrm{Zr}_{80} \mathrm{Cu}_{20}$ & $\mathrm{Zr}_{90} \mathrm{Cu}_{10}$ & \multicolumn{2}{|c|}{$\mathrm{Zr}_{95} \mathrm{Cu}_{5}$} \\
\hline main peak & 37.5 & 36.8 & 35.95 & 35.75 & \multicolumn{2}{|c|}{35.7} \\
\hline
\end{tabular}

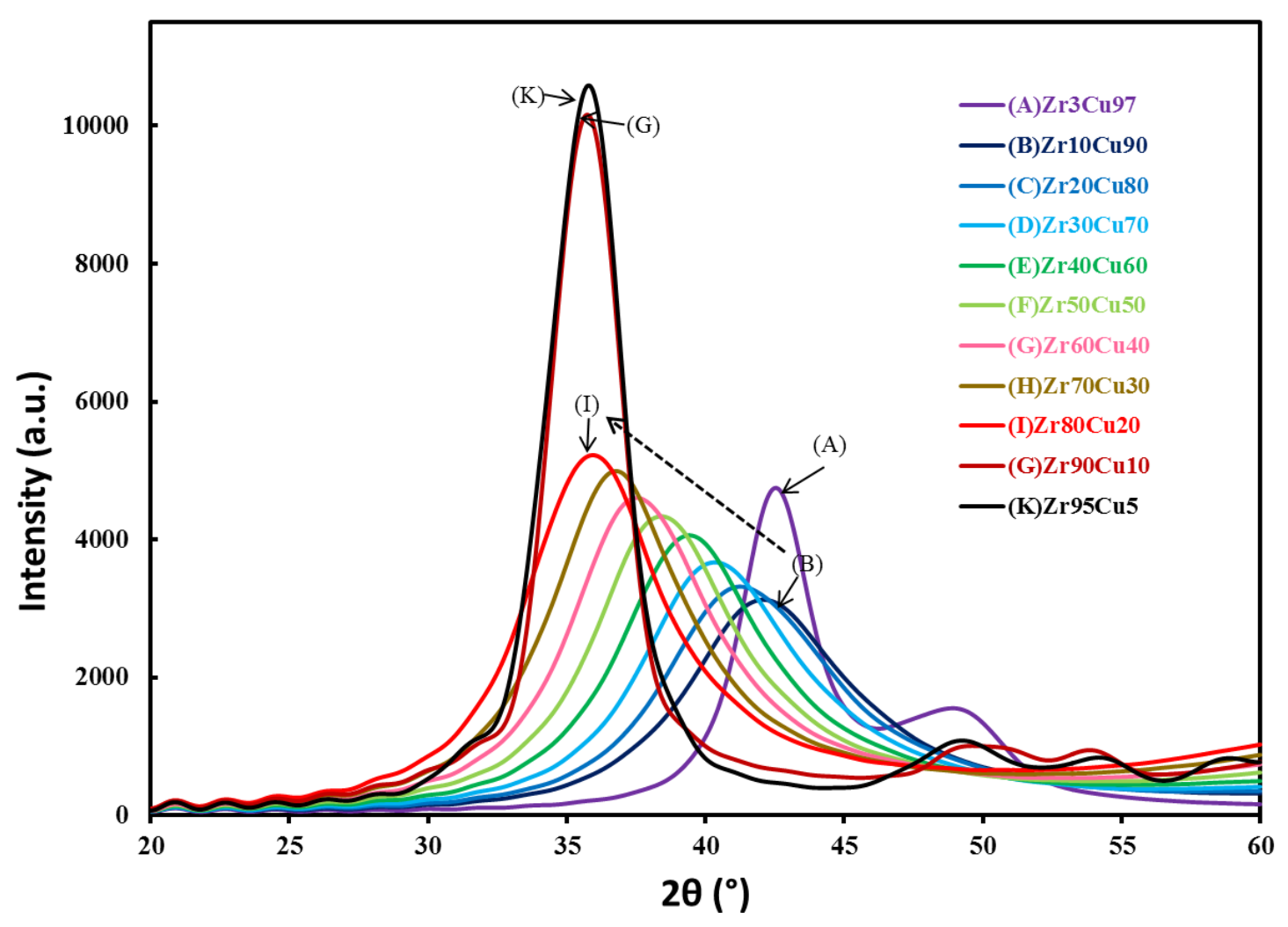

Figure 7: X-Ray intensity vs. $2 \theta$ of $\mathrm{Zr}_{\mathrm{x}} \mathrm{Cu}_{100-\mathrm{x}}$ film with different compositions.

In this condition, for comparison with set 1 of simulations, there is no grain boundary, and the film is single crystalline for $\mathrm{Zr}_{90} \mathrm{Cu}_{10}$ and $\mathrm{Zr}_{95} \mathrm{Cu}_{5}$.

For the highest kinetic energies, $\left\langle\mathrm{E}_{\mathrm{Zr}}\right\rangle=12.6 \mathrm{eV}$ and $\left\langle\mathrm{E}_{\mathrm{Cu}}>=9.61 \mathrm{eV}\right.$, the films exhibit a more compact structure than for previous conditions, with a thickness of approximately $4 \sim 7.5 \mathrm{~nm}$. Corresponding snapshots of the films deposited on the $\mathrm{Si}$ (100) are displayed in Figure 8. 


\section{Zr10Cu9o (947/7820 at.) Zr20Cu80 (1855/6617 at.) Zr30Cu70 (2788/5818 at.)}
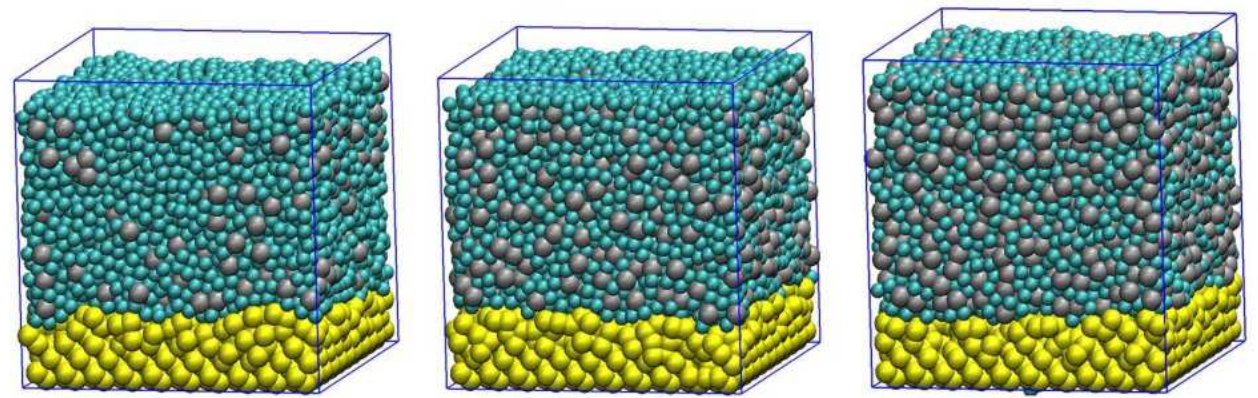

Zr40Cu60 (3682/5018 at.) Zr5oCu50 (4580/4198 at.) Zr60Cu40 (5358/3399 at.)
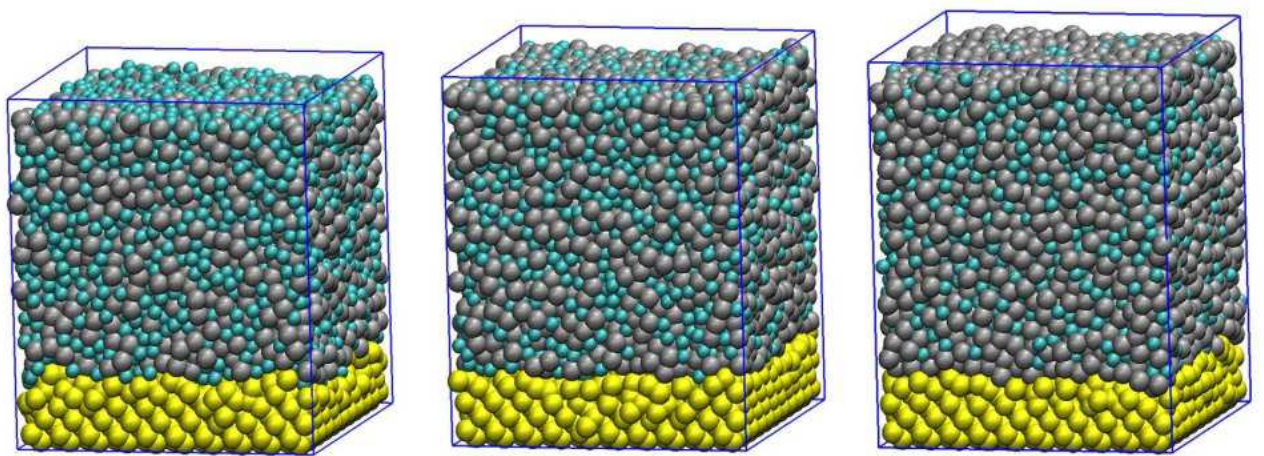

Zr70Сuзo (6248/2584 at.) Zr80Cu20 (7075/1711 at.) Zr9oCu10 (7853/852 at.)
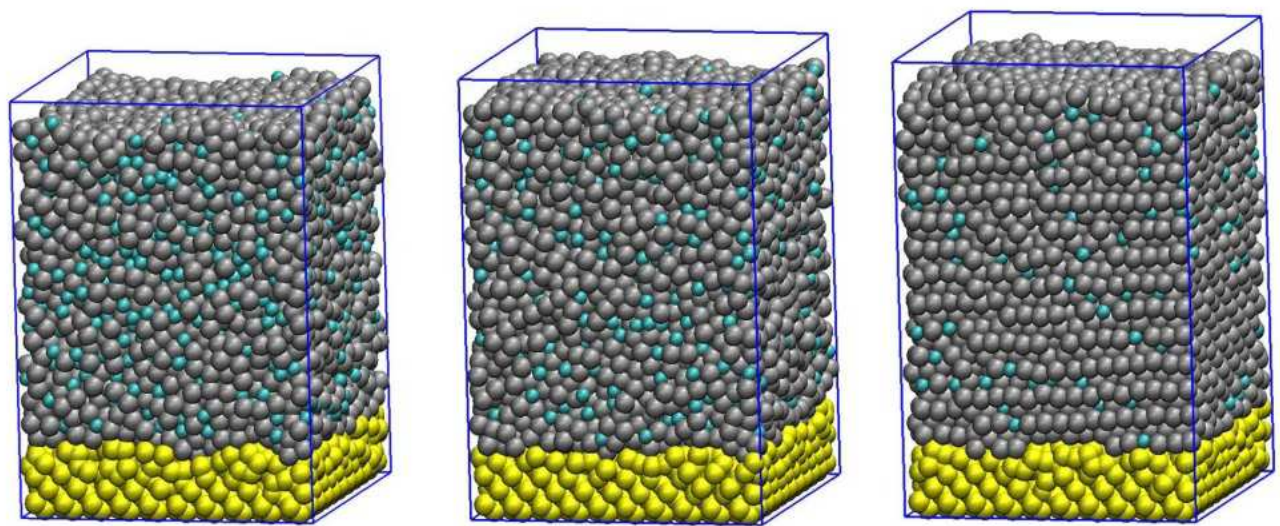

Figure 8: Snapshots of $\mathrm{Zr}-\mathrm{Cu}$ coatings deposited on $\mathrm{Si}(100)$ substrate at different ratios of $\mathrm{Zr}$ and $\mathrm{Cu}$ atoms (the numbers in brackets are the $\mathrm{Zr}$ and $\mathrm{Cu}$ atom numbers respectively). $\bullet \mathrm{Zr}, \bullet \mathrm{Cu}, \bullet \mathrm{Si}$. Mean kinetic energies are $<\mathrm{E}_{\mathrm{Zr}}>=12.6 \mathrm{eV}$ and $<\mathrm{E}_{\mathrm{Cu}}>=9.61 \mathrm{eV}$

Based on these simulations, the total RDF is calculated for each case and is presented in Figure 9. The same trends as previously reported are observed when increasing $\mathrm{Zr}$ concentrations. In the RDF of $\mathrm{Zr}_{90} \mathrm{Cu}_{10}$, four peaks arise up, evidencing a well crystalline structure (Figure 9). From $\mathrm{Zr}_{10} \mathrm{Cu}_{90}$ to 
$\mathrm{Zr}_{80} \mathrm{Cu}_{20}$, the peaks become broad and split evidencing amorphous structures.

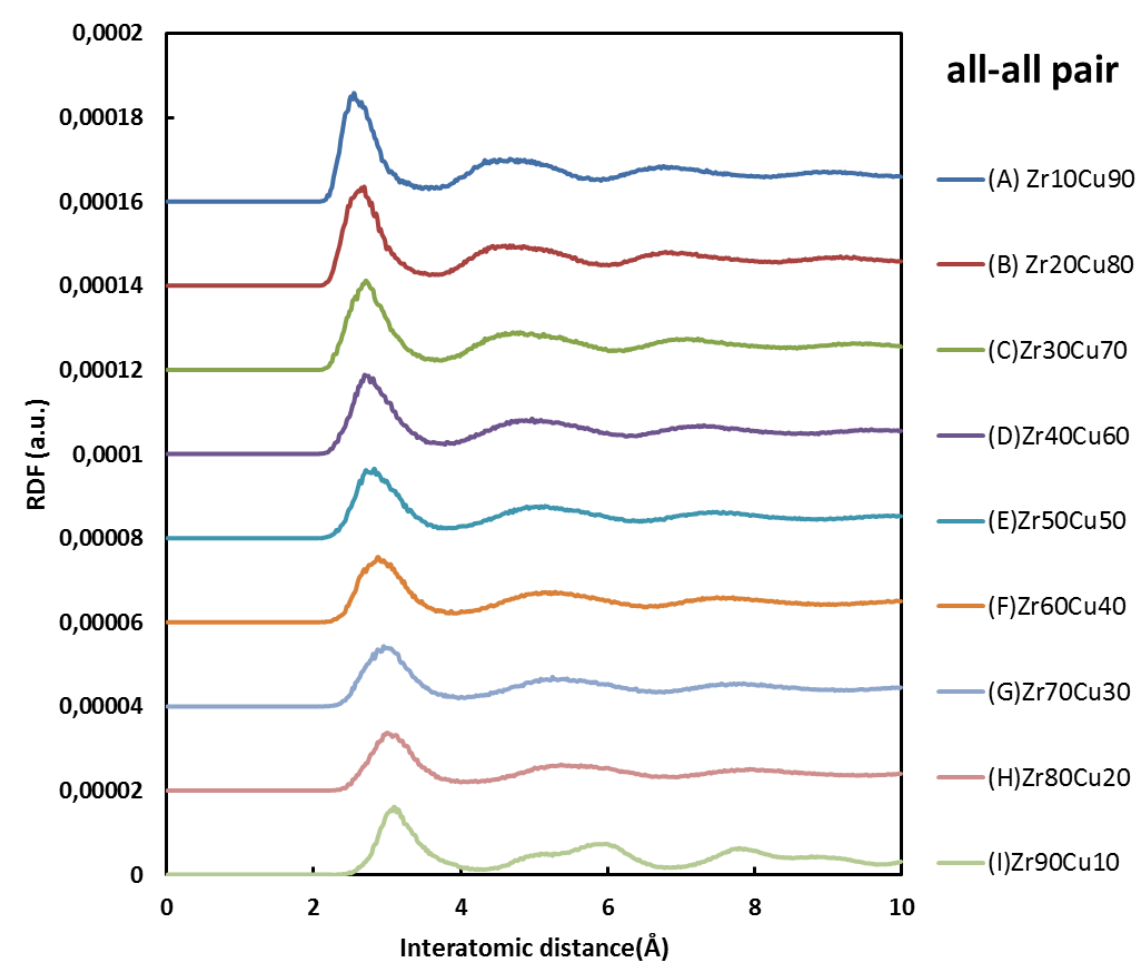

Figure 9: Total RDFs for $\mathrm{Zr}_{\mathrm{x}} \mathrm{Cu}_{100-\mathrm{x}}$ alloys.

Figure 10 shows the intensity and position of the XRD $\theta-2 \theta$ peaks as a function of the $\mathrm{Zr}$ metal content. In this simulation, at the $\mathrm{Zr}$ concentration of $90 \%$, the XRD peak is sharp showing the well crystalline state, which agrees with the RDF presented in figure 9. As the $\mathrm{Zr}$ concentration increases from $10 \%$ to $80 \%$, the peak is broadening indicating an amorphous structure and the peak position shifts towards small angles (Table 4). When comparing these calculated XRD patterns with lower depositing energy, it is seen that $\mathrm{Zr}_{90} \mathrm{Cu}_{10}$ in both sets show a crystallized structure, while for the other ratios an amorphous structure is formed. This indicates the phase and structure of alloy is not much affected by the metal atom kinetic energy in the "high energy" domain. However, Figure 11 shows a specific orientation of the crystal structure of $\mathrm{Zr}_{90} \mathrm{Cu}_{10}$ for simulation sets 2 (A) and 3 (B). It can be seen that snapshot A displays a well crystallized structure, while snapshot B exhibits a crystalline structure capped by an amorphous structure, $1.5 \mathrm{~nm}$ high on the film top.

During the deposition process, the impinging atoms make impacts with the growing film at the surface. 
The kinetic energy of depositing atoms is transferred to the atoms near the impact site and the temperature of the system will locally rise. In order to mimic isothermal growth conditions, Berendsen thermostat was used in an intermediate region above the fixed $\operatorname{Si}(100)$ substrate, for energy dissipating and maintaining the substrate at a desired temperature. For set 2, the large kinetic energy of depositing atoms can be properly dissipated, facilitating the atoms hopping to the sites of stronger binding and forming a continuous crystalline structure. While for set 3 with a higher kinetic energy, the excess energy of the incoming atoms is perturbing the lattice and physically destroying the lattice, limiting the reconstruction.

Table 4: Position of the main XRD peak for $\mathrm{ZrCu}$ alloy in the simulation. Unit: $2 \theta\left(^{\circ}\right)$

\begin{tabular}{|c|c|c|c|c|c|}
\hline $\mathrm{Zr}-\mathrm{Cu}$ & $\mathrm{Zr}_{10} \mathrm{Cu}_{90}$ & $\mathrm{Zr}_{20} \mathrm{Cu}_{80}$ & $\mathrm{Zr}_{30} \mathrm{Cu}_{70}$ & $\mathrm{Zr}_{40} \mathrm{Cu}_{60}$ & $\mathrm{Zr}_{50} \mathrm{Cu}_{50}$ \\
\hline main peak & 41.85 & 41.3 & 40.2 & 39.15 & 38.2 \\
\hline $\mathrm{Zr}-\mathrm{Cu}$ & $\mathrm{Zr}_{60} \mathrm{Cu}_{40}$ & $\mathrm{Zr}_{70} \mathrm{Cu}_{30}$ & $\mathrm{Zr}_{80} \mathrm{Cu}_{20}$ & \multicolumn{2}{|c|}{$\mathrm{Zr}_{90} \mathrm{Cu}_{10}$} \\
\hline main peak & 37.55 & 36.75 & 35.7 & \multicolumn{2}{|c|}{35.65} \\
\hline
\end{tabular}

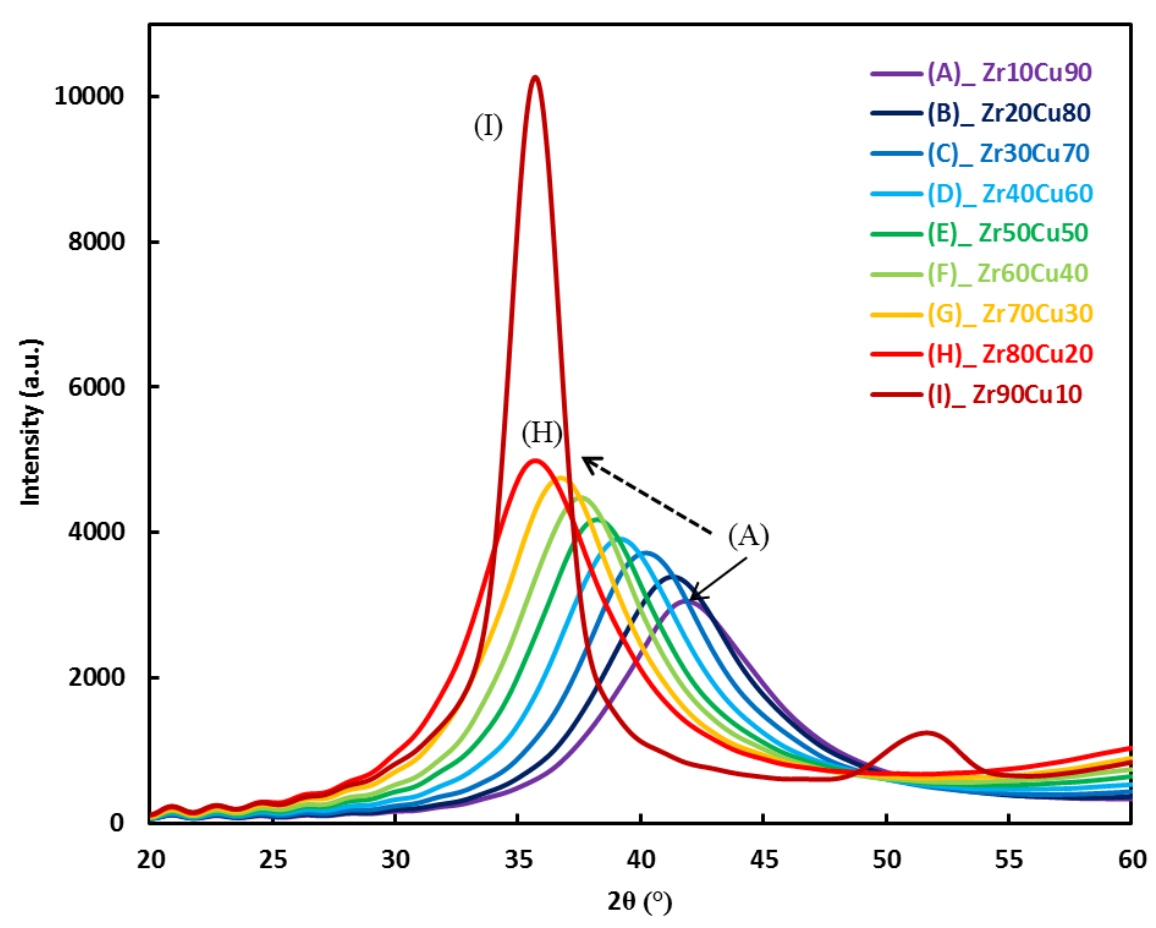

Figure 10: Calculated X-Ray intensity vs. $2 \theta$ of $\mathrm{Zr}_{\mathrm{x}} \mathrm{Cu}_{100-\mathrm{x}}$ film with different compositions. 


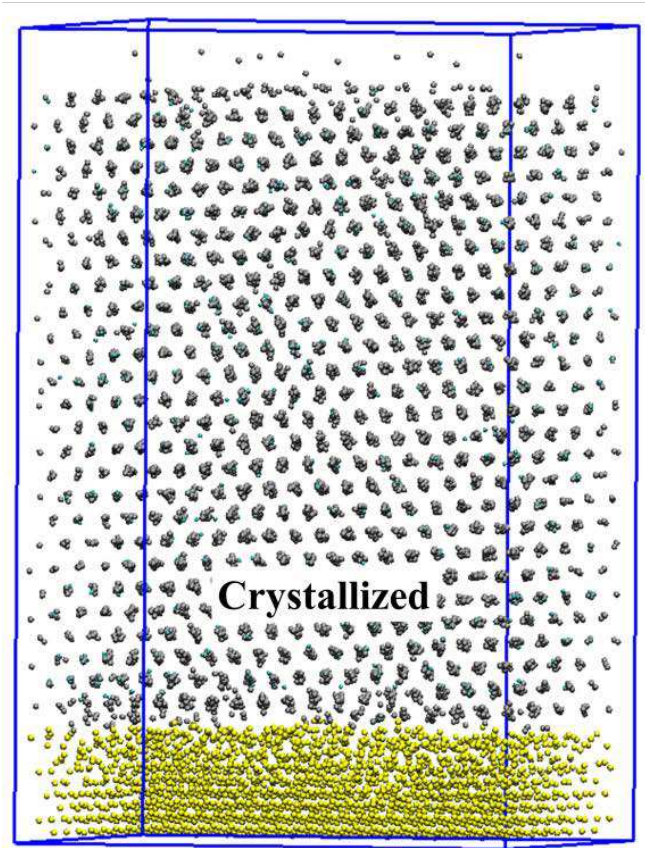

(A)

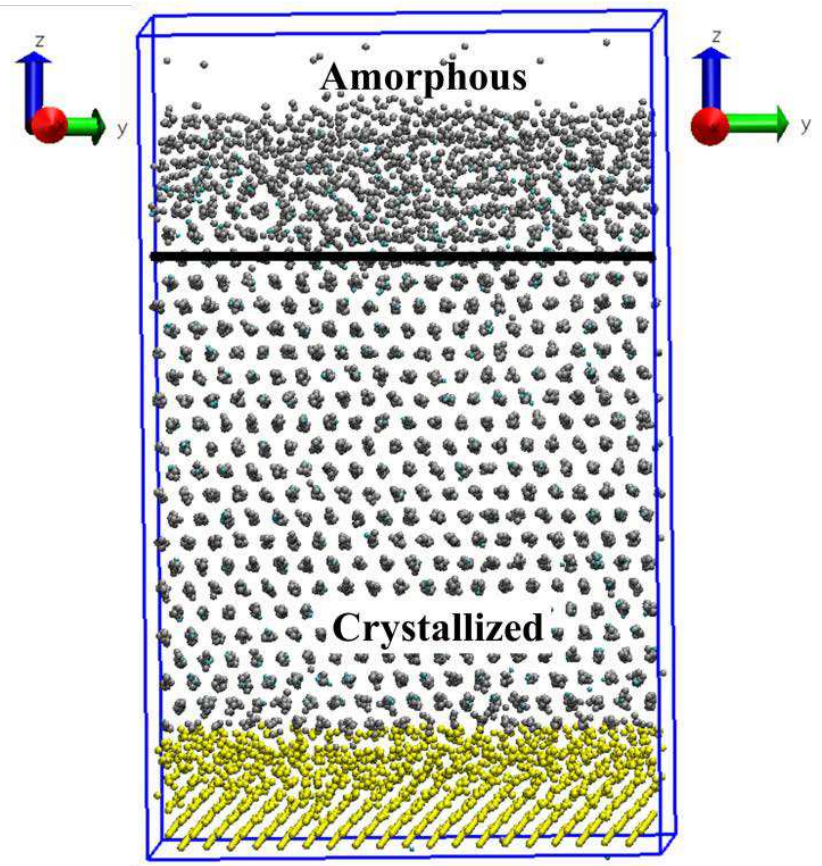

(B)

Figure 11: Snapshots of $\mathrm{Zr}_{90} \mathrm{Cu}_{10}$ with condition 2 (A) and 3 (B) grown on $\mathrm{Si}(100)$ substrate with their specific orientation showing the crystal structure. Solid line in (B) is used to separate the amorphous and crystalline zones.

\section{Case study 2: Molecular dynamics simulation of AlCoCrCuFeNi high entropy alloy thin film deposition onto silicon}

High Entropy Alloys (HEA) are metallic compounds containing six to 13 elements with a concentration in the range 5 to $35 \%$ for each element (Yeh, 2006, Zhang, 2014). In these alloys, because of the high entropy of mixing, formation of brittle intermetallic phases are avoided and multielement solid solutions are stabilized (fcc and/or bcc) (Yang, 2012). The combination of numerous metallic elements with different sizes induces a sluggish atomic diffusion, leading to nanocrystalline or amorphous structures. Bulk HEAs have been extensively studied for their excellent properties and performance, including outstanding strength and resistance to oxidation at high temperatures, anti-adhesion, corrosion resistance, high temperature stability, hydrophobicity, high stiffness, strength and toughness, high hardness and high-strain-rate superplasticity (Hsu, 2007; Wu, 2006; Lin, 2011) . However, HEAs are quite difficult to synthesize as bulk materials and, for many 
applications, transferring their exceptional properties to a bare material may be of interest. Few studies on HEA thin films deposited by magnetron sputtering have been published (Yeh, 2004; Chang 2008; Tsai, 2008; Chen, 2004, 2005; Dolique, 2009, 2010) starting from alloyed targets formed by melting or casting, or from mosaic ones (Dolique, 2009, 2010). HEAs can be viewed as atomic-scale composites. Their final properties come from 1) the combination of properties of their constituting elements and 2) the stabilized solid solutions and structures. Thus for the design of new alloys dedicated to a given application, prediction of structural features of the thin film would be of particular interest. Despite this applicative goal, understanding of the growth mode of such complex multielement films is a challenging research subject. Available literature on metallic alloy thin film growth allows thus carrying out simulation of the process at the atomic level.

The present section is devoted to molecular dynamics simulations for studying growth of complex HEA thin films. The integration time-step is chosen to be $1 \mathrm{fs}$. The HEA atoms impinge on $\mathrm{Si}(100)$ substrate with velocities sampled in a Maxwell-Boltzann distribution leading to an incident mean kinetic energy of $1 \mathrm{eV}$. Two substrate sizes are chosen for the subsequent simulations: 1) $\operatorname{Si}(100)$ with dimensions $(100 \times 100 \times 20) \AA, 2) \operatorname{Si}(100)$ with dimensions $(17 \times 17 \times 20) \AA^{2}$. The deposition model of the six atoms is shown in Figure 12.

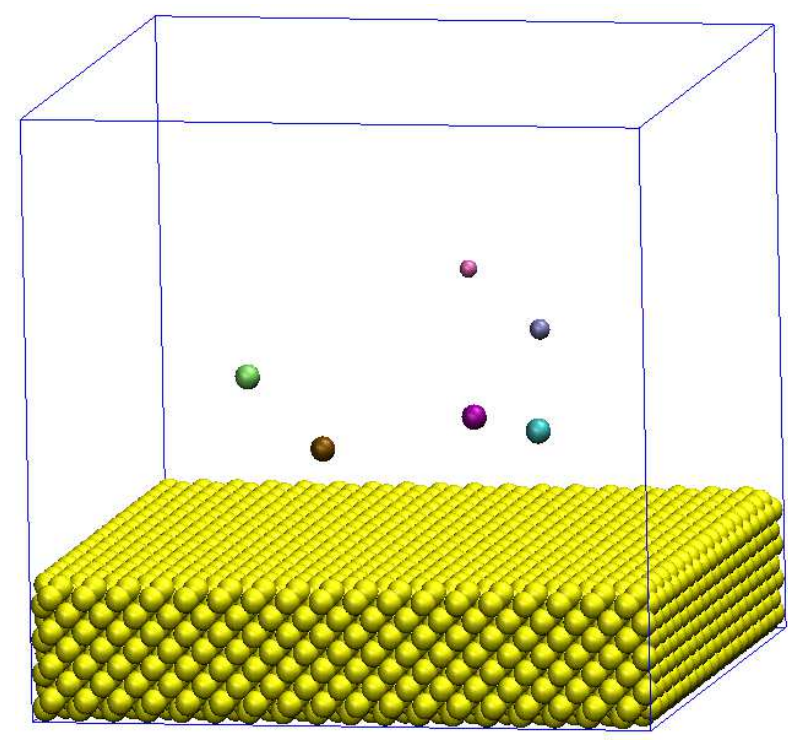

Figure 12: Schematic picture of the initial HEA deposition model. $\bullet \mathrm{Al}, \bullet \mathrm{Co}, \bullet \mathrm{Cr}, \bullet \mathrm{Cu}, \bullet \mathrm{Fe}$, $\bullet \mathrm{Ni}, \mathrm{Si}$ 
Three sets of MD simulations of AlCoCrCuFeNi HEA thin films with different element composition are made, according to DC magnetron sputtering experimental conditions. X-ray diffraction analysis ( $\mathrm{Cu} \mathrm{K} \mathrm{\alpha}_{\alpha}$ radiation, $\lambda=0.15405 \mathrm{~nm}$, Bragg-Brentano geometry) was performed.

During MD simulation, 10000 atoms are released to the Si surface for realizing three deposition sets. A random number $\mathrm{x}$ is generated for selecting the nature of the atom to be released, where $0 \leq \mathrm{x}<100$.

Taking $\mathrm{Al}_{2} \mathrm{Co}_{9} \mathrm{Cr}_{32} \mathrm{Cu}_{39} \mathrm{Fe}_{12} \mathrm{Ni}_{6}$ as an example, $\mathrm{Al}$ is chosen if $0 \leq \mathrm{x}<2$, Co if $3 \leq \mathrm{x}<11, \mathrm{Cr}$ if $11 \leq \mathrm{x}<$ 43 and so on. With this method the desired number of different atom types can be properly selected according to the expected film composition. The outputs of simulations will inform about whether targeted composition is reached. Table 5 gives the number of atoms really living in the simulated film and its composition. The compositions of the simulated samples are close to the targeted ones.

Table 5: Targeted and simulated deposited alloy compositions

\begin{tabular}{|l|c|c|c|c|c|c|}
\hline Atoms & $\mathrm{Al}$ & $\mathrm{Co}$ & $\mathrm{Cr}$ & $\mathrm{Cu}$ & $\mathrm{Fe}$ & $\mathrm{Ni}$ \\
\hline Sample S1 & \multicolumn{5}{|c|}{$\mathrm{Al}_{2} \mathrm{Co}_{9} \mathrm{Cr}_{32} \mathrm{Cu}_{39} \mathrm{Fe}_{12} \mathrm{Ni}_{6}(8630 / 10000)$} \\
\hline Deposited number & 151 & 956 & 2835 & 3211 & 1023 & 454 \\
\hline Simulation composition & $1,7 \%$ & $11,1 \%$ & $32,9 \%$ & $37,2 \%$ & $11,9 \%$ & $5,3 \%$ \\
\hline Targeted composition & $2 \%$ & $9 \%$ & $32 \%$ & $39 \%$ & $11 \%$ & $6 \%$ \\
\hline Sample S2 & \multicolumn{7}{|c|}{$\mathrm{Al}_{3} \mathrm{Co}_{26} \mathrm{Cr}_{15} \mathrm{Cu}_{18} \mathrm{Fe}_{20} \mathrm{Ni}_{18}(8466 / 10000)$} \\
\hline Deposited number & 237 & 2154 & 1214 & 1550 & 1692 & 1619 \\
\hline Simulation composition & $2,8 \%$ & $25,4 \%$ & $14,3 \%$ & $18,3 \%$ & $20,0 \%$ & $19,1 \%$ \\
\hline Targeted composition & $3 \%$ & $26 \%$ & $15 \%$ & $18 \%$ & $20 \%$ & $18 \%$ \\
\hline Sample S3 & \multicolumn{7}{|c|}{$\mathrm{Al}_{39} \mathrm{Co}_{10} \mathrm{Cr}_{14} \mathrm{Cu}_{18} \mathrm{Fe}_{13} \mathrm{Ni}_{6}(8680 / 10000)$} \\
\hline Deposited number & 2977 & 1084 & 1222 & 1688 & 1146 & 563 \\
\hline Simulation composition & $34,3 \%$ & $12,5 \%$ & $14,1 \%$ & $19,4 \%$ & $13,2 \%$ & $6,5 \%$ \\
\hline Targeted composition & $39 \%$ & $10 \%$ & $14 \%$ & $18 \%$ & $13 \%$ & $6 \%$ \\
\hline
\end{tabular}

\subsection{MD simulation of HEA deposition on large Si(100)}

Sample simulation snapshots for $\mathrm{Al}_{2} \mathrm{Co}_{9} \mathrm{Cr}_{32} \mathrm{Cu}_{39} \mathrm{Fe}_{12} \mathrm{Ni}_{6}, \quad \mathrm{Al}_{3} \mathrm{Co}_{26} \mathrm{Cr}_{15} \mathrm{Cu}_{18} \mathrm{Fe}_{20} \mathrm{Ni}_{18}$ and $\mathrm{Al}_{39} \mathrm{Co}_{10} \mathrm{Cr}_{14} \mathrm{Cu}_{18} \mathrm{Fe}_{13} \mathrm{Ni}_{6}$ thin films are reported in figure 13. In all cases, there is no continuous film 
growth and the deposits grow as various sized clusters, more or less meandering, due to the limited number of impinging atoms and the large simulation cell size. The cluster mean height is around $3 \sim$ $3.5 \mathrm{~nm}$ for 10000 released atoms.
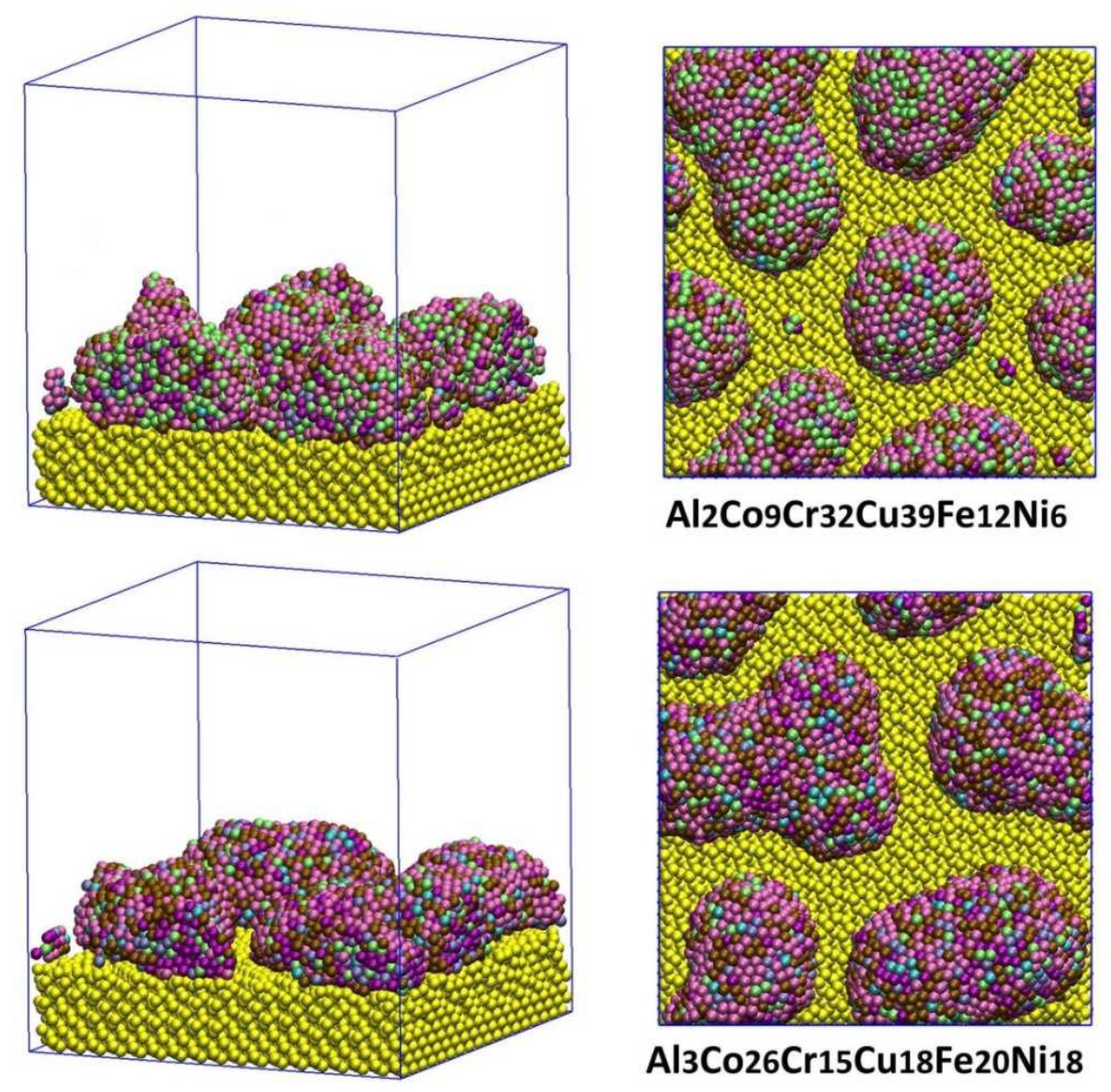

Al3Co26Cr15Cu18Fe20Ni18
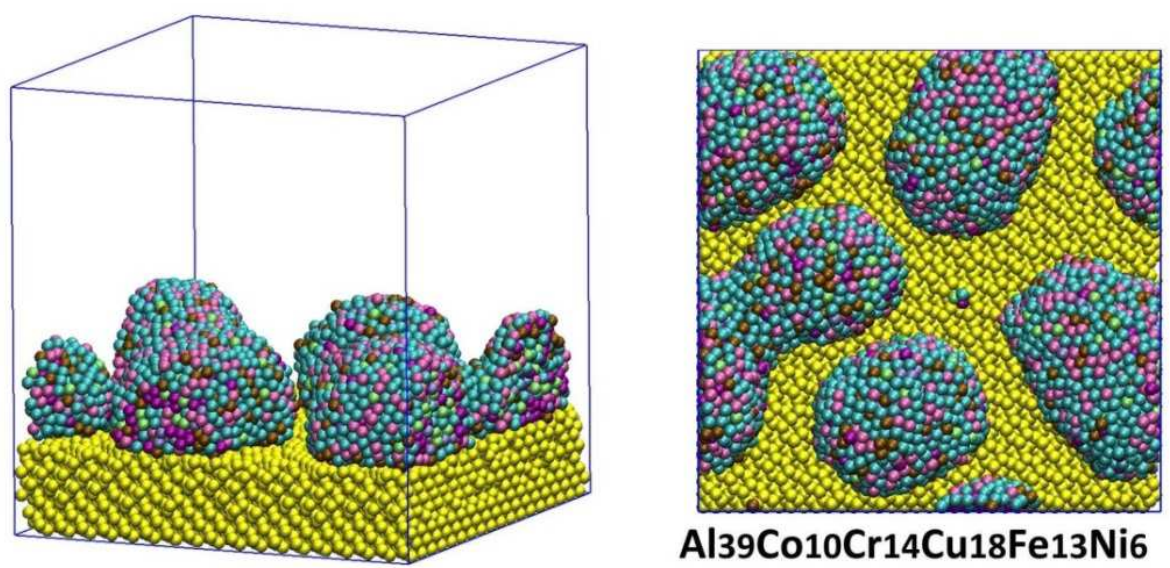

Al39Co10Cr14Cu18Fe13Ni6

Figure 13: Snapshots of HEA films deposited on $\mathrm{Si}(100)$ substrate with large substrate $\bullet \mathrm{Al}, \bullet \mathrm{Co}$, $\bullet \mathrm{Cr}, \bullet \mathrm{Cu}, \bullet \mathrm{Fe}, \bullet \mathrm{Ni}, \bullet \mathrm{Si}$

The RDF for the three samples was then calculated and is plotted in Figure 14. The peaks represent the 
successive neighbour distances of the atoms, which can be compared with the corresponding values in crystalline phases of each element (see Table 6).

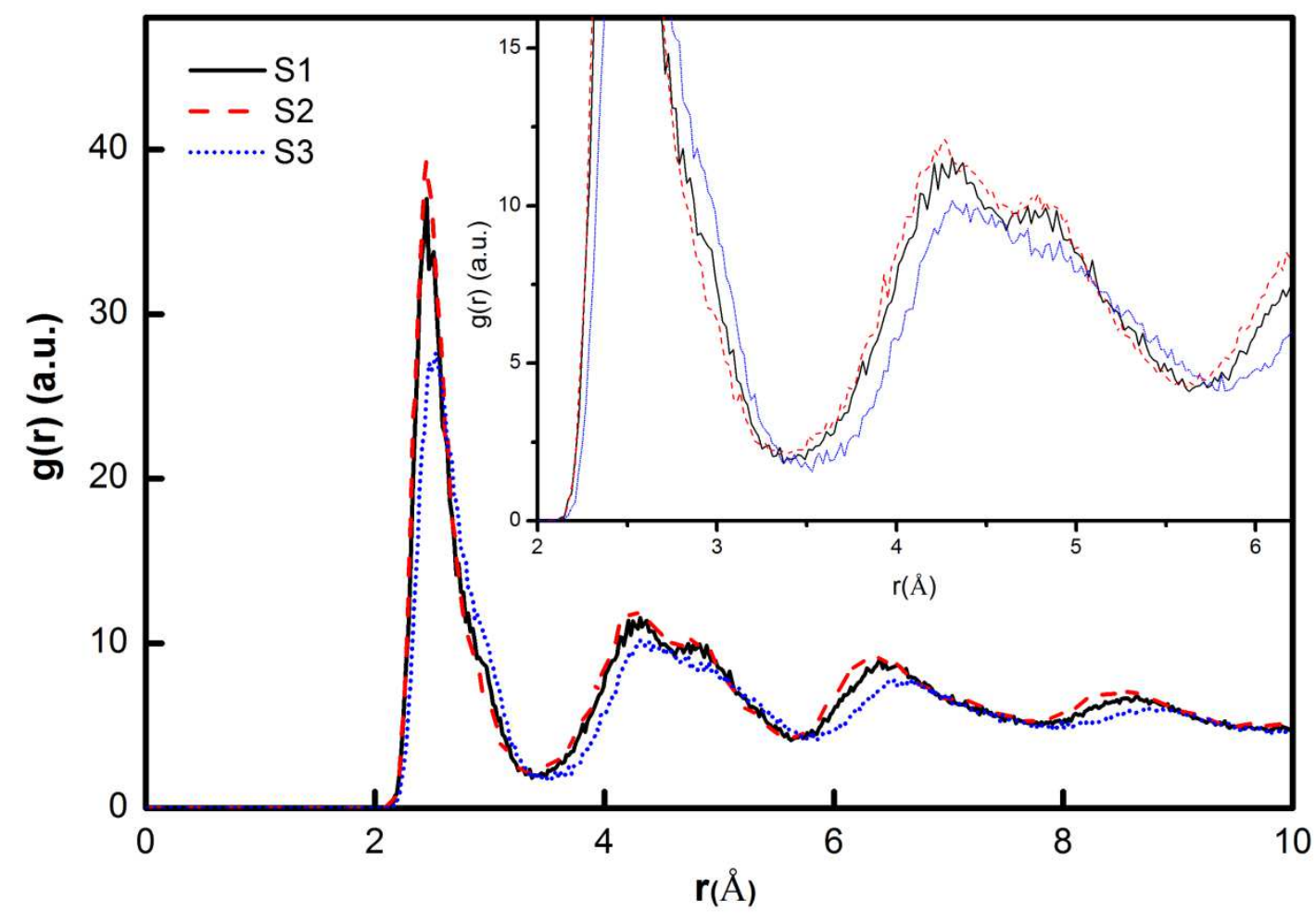

Figure 14: Total RDF of the HEA deposit at different compositions.

Table 6: The neighbour distances in single element crystal.

\begin{tabular}{|c|c|c|c|c|c|}
\hline Elements & $\begin{array}{c}\text { Lattice } \\
\text { parameter }(\AA)\end{array}$ & $\begin{array}{c}1^{\text {st }} \text { neighbor } \\
(\AA)\end{array}$ & $\begin{array}{c}2^{\text {nd }} \text { neighbor } \\
(\AA)\end{array}$ & $\begin{array}{c}3^{\text {rd }} \text { neighbor } \\
(\AA)\end{array}$ & $\begin{array}{c}4^{\text {th }} \text { neighbor } \\
(\AA)\end{array}$ \\
\hline $\mathrm{Al}(\mathrm{fcc})$ & $\mathrm{a}_{\mathrm{Al}}=4.05$ & $\frac{\mathrm{a}_{\mathrm{Al}}}{\sqrt{2}}=2.86$ & $\mathrm{a}_{\mathrm{Al}}=4.05$ & $\sqrt{\frac{3}{2}} \mathrm{a}_{\mathrm{Al}}=4.96$ & $\sqrt{2} \mathrm{a}_{\mathrm{Al}}=5.73$ \\
\hline Co (hcp) & $\begin{array}{l}\mathrm{a}_{\mathrm{Co}}=2.51 \\
\mathrm{c}_{\mathrm{Co}}=4.07\end{array}$ & $\mathrm{a}_{\mathrm{Co}}=2.51$ & $\sqrt{2} \mathrm{a}_{\mathrm{Co}}=3.09$ & $\mathrm{c}_{\mathrm{Co}}=4.07$ & $\sqrt{2} \mathrm{c}_{\mathrm{Co}}=5.76$ \\
\hline $\mathrm{Cu}(\mathrm{fcc})$ & $\mathrm{a}_{\mathrm{Cu}}=3.61$ & $\frac{\mathrm{a}_{\mathrm{Cu}}}{\sqrt{2}}=2.55$ & $\mathrm{a}_{\mathrm{Cu}}=3.61$ & $\sqrt{\frac{3}{2}} \mathrm{a}_{\mathrm{Cu}}=4.42$ & $\sqrt{2} \mathrm{a}_{\mathrm{Cu}}=5.10$ \\
\hline $\mathrm{Cr}(\mathrm{bcc})$ & $\mathrm{a}_{\mathrm{Cr}}=2.88$ & $\frac{\sqrt{3}}{2} \mathrm{a}_{\mathrm{Cr}}=2.49$ & $\mathrm{a}_{\mathrm{Cr}}=2.88$ & $\sqrt{2} \mathrm{a}_{\mathrm{Cr}}=4.07$ & $\sqrt{\frac{11}{4}} \mathrm{a}_{\mathrm{Cr}}=4.78$ \\
\hline $\mathrm{Fe}(\mathrm{bcc})$ & $\mathrm{a}_{\mathrm{Fe}}=2.87$ & $\frac{\sqrt{3}}{2} \mathrm{a}_{\mathrm{Fe}}=2.49$ & $\mathrm{~A}_{\mathrm{Fe}}=2.87$ & $\sqrt{2} \mathrm{a}_{\mathrm{Fe}}=4.06$ & $\sqrt{\frac{11}{4}} \mathrm{a}_{\mathrm{Fe}}=4.76$ \\
\hline
\end{tabular}




\begin{tabular}{|c|l|l|l|l|l|}
\hline $\mathrm{Ni}(\mathrm{fcc})$ & $\mathrm{a}_{\mathrm{Ni}}=3.52$ & $\frac{\mathrm{a}_{\mathrm{Ni}}}{\sqrt{2}}=2.49$ & $\mathrm{a}_{\mathrm{Ni}}=3.52$ & $\sqrt{\frac{3}{2}} \mathrm{a}_{\mathrm{Ni}}=4.31$ & $\sqrt{2} \mathrm{a}_{\mathrm{Ni}}=4.98$ \\
\hline
\end{tabular}

Table 7: Average neighbour distances in the HEA.

\begin{tabular}{|l|c|c|c|c|}
\hline Elements & $1^{\text {st }}$ neighbor & $2^{\text {nd }}$ neighbor & $3^{\text {rd }}$ neighbor & $4^{\text {th }}$ neighbor \\
\hline $\mathrm{Al}_{2} \mathrm{Co}_{9} \mathrm{Cr}_{32} \mathrm{Cu}_{39} \mathrm{Fe}_{12} \mathrm{Ni}_{6}$ (average) & 2.52 & 3.19 & 4.32 & 4.99 \\
\hline Sample1 & 2.44 & - & 4.27 & 4.79 \\
\hline $\mathrm{Al}_{3} \mathrm{Co}_{26} \mathrm{Cr}_{15} \mathrm{Cu}_{18} \mathrm{Fe}_{20} \mathrm{Ni}_{18}$ (average) & 2.52 & 3.19 & 4.19 & 5.14 \\
\hline Sample2 & 2.45 & - & 4.30 & 4.83 \\
\hline $\mathrm{Al}_{39} \mathrm{Co}_{10} \mathrm{Cr}_{14} \mathrm{Cu}_{18} \mathrm{Fe}_{13} \mathrm{Ni}_{6}$ (average) & 2.64 & 3.49 & 4.48 & 5.3 \\
\hline Sample3 & 2.46 & - & 4.35 & - \\
\hline
\end{tabular}

As displayed in Table 7, the average values are calculated by $<\mathrm{r}_{\text {neighbour }}>=\sum_{\mathrm{i}=1, \mathrm{n}} \mathrm{c}_{\mathrm{i}} \mathrm{R}_{\mathrm{i}}$ according to the element crystal values presented in Table 6 , where $c_{i}$ is the atomic percentage of the $i^{\text {th }}$ component and $R_{i}$ is the neighbour distances of $i^{\text {th }}$ HEA element in pure crystal. By analyzing the average neighbour distances value of HEA in Table 7, we can see that the first neighbour distance is almost the same in these three samples and around $2.45 \AA$. The expected $2^{\text {nd }}$ neighbour distance does not appear in the simulated thin film. This can be explained by the hard ball model (Kao, 2008) and attributed to the effect of mixing numerous elements with different atomic sizes as depicted in Figure 15. The circles represent the first, second, third, fourth and fifth shells, respectively. Because the system is compact, the first shell will be stable or only change a little bit due to the presence of neighbour atoms with different atomic radius. However the second and third shells are indistinguishable because of the large fluctuation in occupation of different sites. This introduces the disappearance of the second peak in RDFs. 


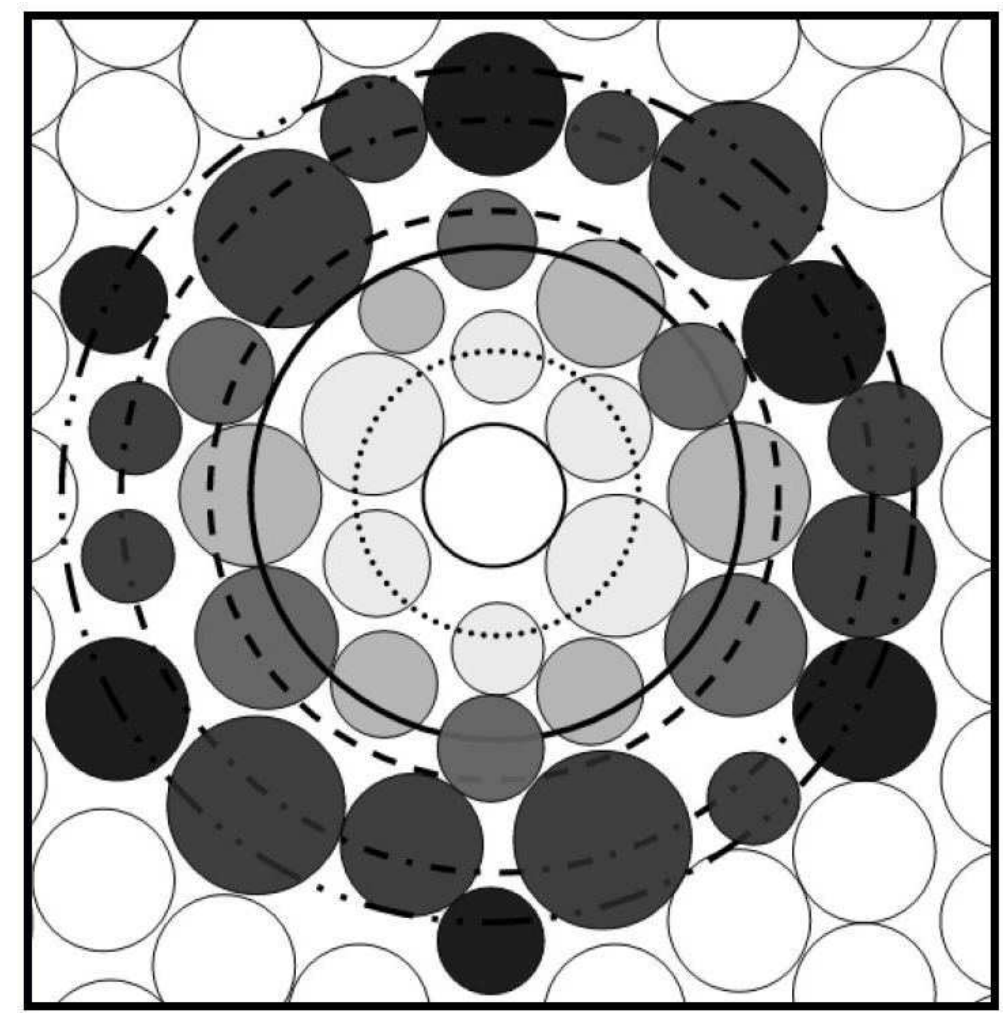

Figure 15: Hard ball model for HEA (reprinted from Kao, 2008)

A further insight can be achieved by comparing experimental XRD patterns with those calculated in the simulation. The recorded XRD $\theta-2 \theta$ peaks are shown in figure 16, where the corresponding diffraction spectra (limited to the $\theta-2 \theta$ range where the main peak of FCC and BCC phases lies) are given. The following peak positions are observed: $2 \theta=43.77^{\circ}$ for sample 3 and $2 \theta=43.81^{\circ}$ for sample 1 attributed to the fcc(111) $\beta$ structure, $2 \theta=44.41^{\circ}$ for sample 2 attributed to the $\operatorname{bcc}(110) \alpha$ structure. However, the broad and low intensity sample 2 peaks could indicate a mixture of both solid solutions and a less ordered phase. 


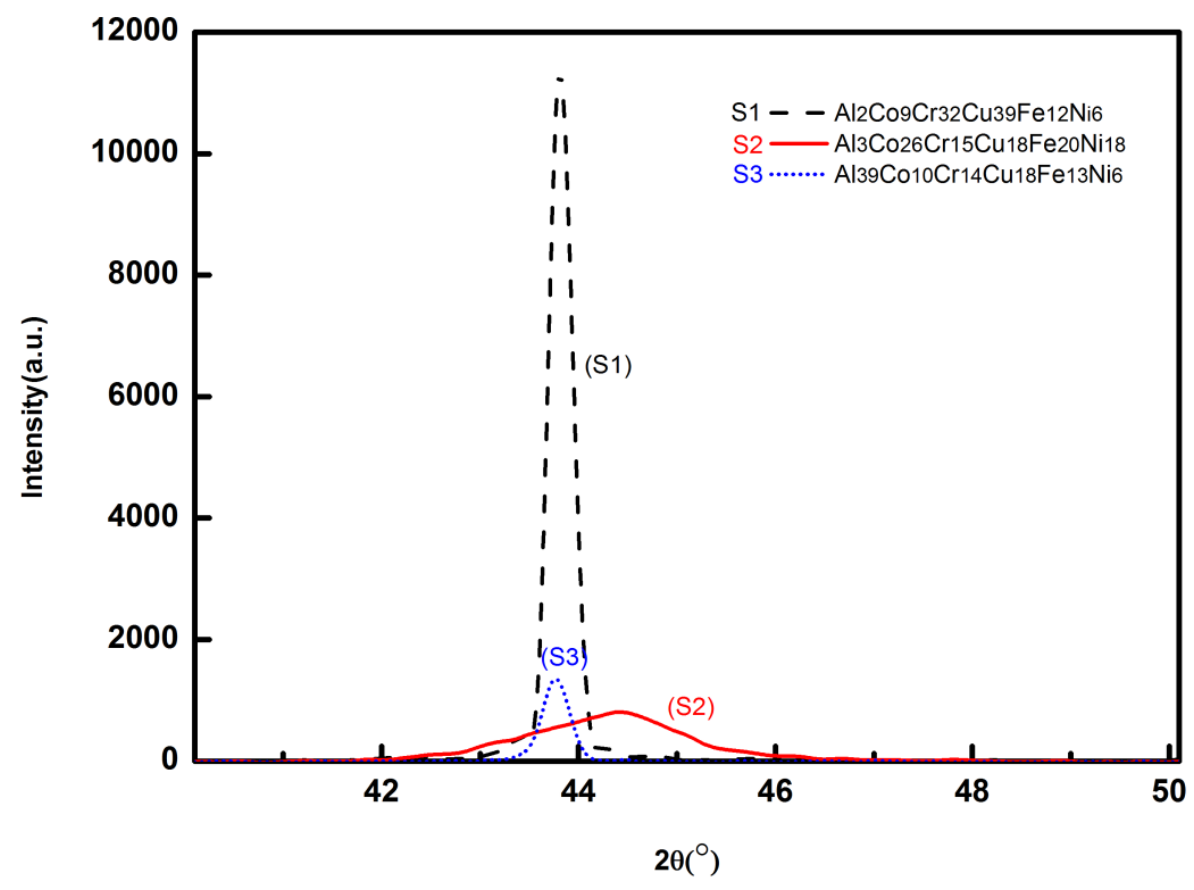

Figure 16: Experimental XRD patterns of HEA film sputtered at $300 \mathrm{~K}$ with different compositions

The calculated X-ray intensities vs. $2 \theta$ of HEA samples are shown in Figure 17. By comparing both XRD plot sets, it can be observed that the peak positions in the simulated XRD are close to that detected in the experimental XRD patterns (see Table 8).

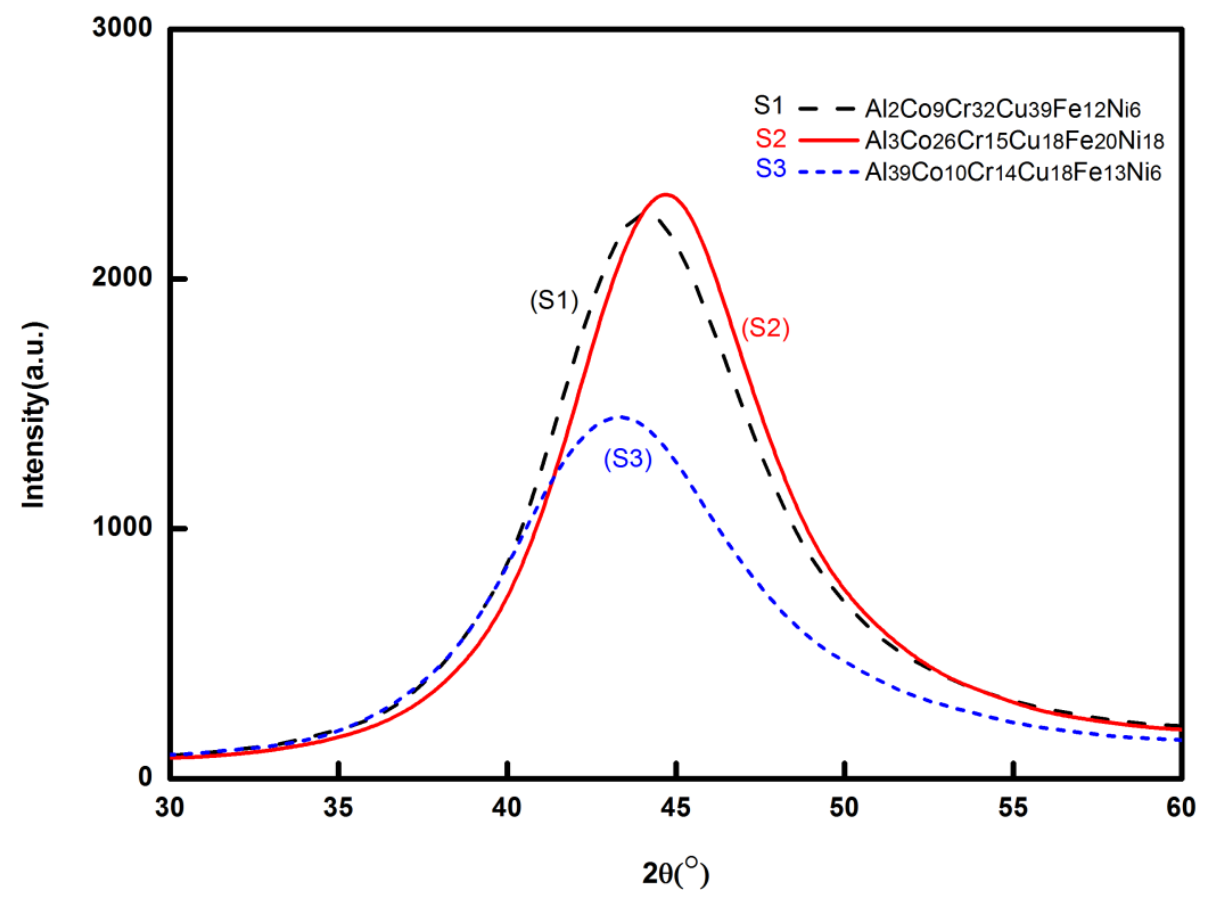

Figure 17: The simulated XRD patterns at different compositions. 
Table 8: $2 \theta$ positions of first XRD peaks for HEA in the experiment and simulation

Experiment

Unit: $2 \theta\left(^{\circ}\right)$

\begin{tabular}{|c|c|c|c|}
\hline HEA & $\mathrm{Al}_{39} \mathrm{Co}_{10} \mathrm{Cr}_{14} \mathrm{Cu}_{18} \mathrm{Fe}_{13} \mathrm{Ni}_{6}$ & $\mathrm{Al}_{2} \mathrm{Co}_{9} \mathrm{Cr}_{32} \mathrm{Cu}_{39} \mathrm{Fe}_{12} \mathrm{Ni}_{6}$ & $\mathrm{Al}_{3} \mathrm{Co}_{26} \mathrm{Cr}_{15} \mathrm{Cu}_{18} \mathrm{Fe}_{20} \mathrm{Ni}_{18}$ \\
\hline Main peak & 43.77 & 43.81 & 44.41 \\
\hline Simulation & \multicolumn{3}{|c|}{$\mathrm{Unit}_{2} 2 \theta\left({ }^{\circ}\right)$} \\
\hline HEA & $\mathrm{Al}_{39} \mathrm{Co}_{10} \mathrm{Cr}_{14} \mathrm{Cu}_{18} \mathrm{Fe}_{13} \mathrm{Ni}_{6}$ & $\mathrm{Al}_{2} \mathrm{Co}_{9} \mathrm{Cr}_{32} \mathrm{Cu}_{39} \mathrm{Fe}_{12} \mathrm{Ni}_{6}$ & $\mathrm{Al}_{3} \mathrm{Co}_{26} \mathrm{Cr}_{15} \mathrm{Cu}_{18} \mathrm{Fe}_{20} \mathrm{Ni}_{18}$ \\
\hline Main peak & 43.95 & 44.1 & 44.7 \\
\hline
\end{tabular}

As can be seen from figure 16 and 17, peak intensities are very different between simulations and experiments. However, the three experimental peak intensities are not comparable among them, due to different set of XRD measurements. Thus no conclusion between experimental and simulated peak intensity evolution can be drawn. This shows that such comparison can only be qualitative.

\subsection{Simulations of HEA film growth on a reduced size Si(100) substrate.}

In the previous section, we found that HEA clusters are formed after 10000 HEA atoms being released on the substrate. If we increase the number of the deposit atoms, we can expect to evolve towards a continuous film morphology. But this will cost too much calculation time. Another method is to reduce the width of the box: the width of the new substrate cell is thus set to dimensions $(17 \times 17) \AA^{2}$. The length in $\mathrm{x}$ and $\mathrm{y}$ direction is thus $1 / 6$ of the previous size. In other words, if the same height is reached, the volume of the new simulation box is $1 / 36$ of the previous size box.

The interaction cut-off distances are set to $8 \AA$. The width of the system was thus chosen in a way that each dimension would be at least twice the cut-off. So boundary effects are expected to be limited. With this smaller width, if the velocity of deposited atom is too large along $\mathrm{x}$ and $\mathrm{y}$ directions, it will pass through the periodic boundary several times. This will affect the whole system and may introduce artefacts in the morphology. Figure 18 displays the trajectory of a typical $\mathrm{Cu}$ atom in the process of deposition in sample 1. The small blue balls and the blue line represent the position history of the moving $\mathrm{Cu}$ atom. Each position is separated by a 4 ps travel time and $\mathrm{Cu}$ atom can be captured by the nearby surface atoms with a fast relaxation. This typical trajectory shows that this small substrate size can be used for the MD simulations of HEA film growth without any effect of the periodic boundary condition. It can also be noticed that such systems (HEA) are expect not to form large range order, due 
to size differences and thus preventing long range diffusion leading to segregation.

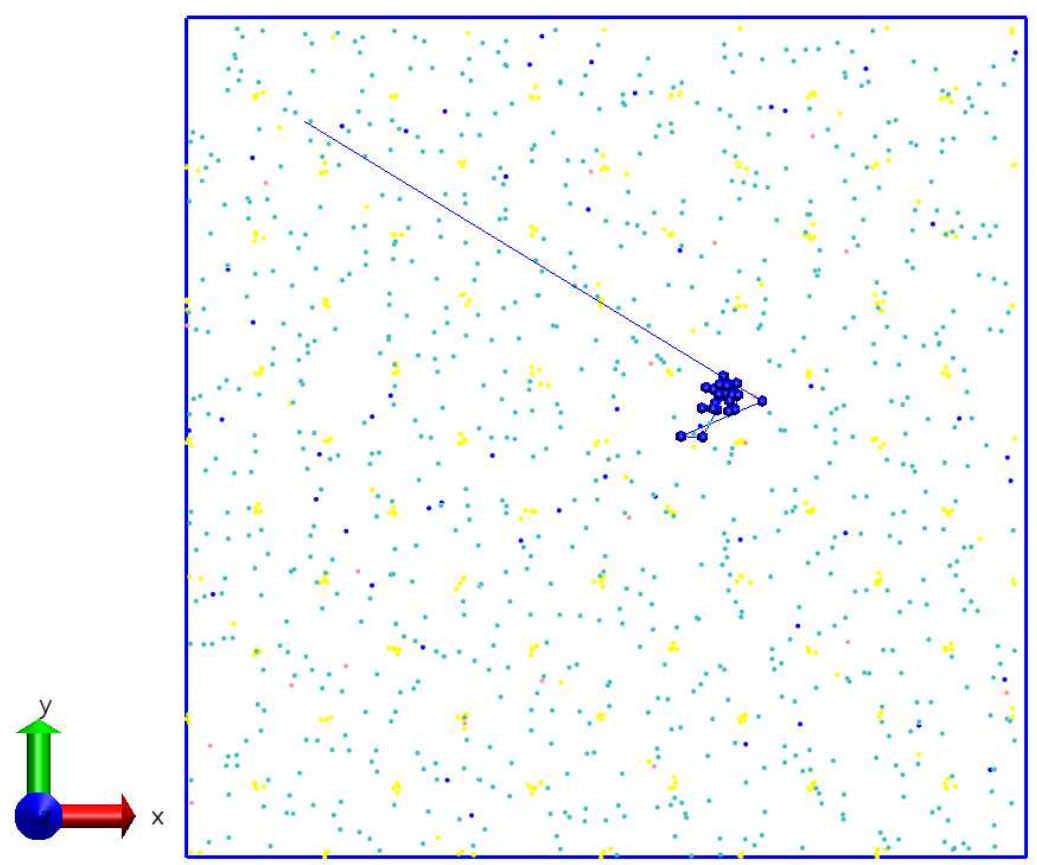

Figure 18: Projected $\mathrm{Cu}$ atom during deposition (cross section of the cell along $\mathrm{z}$ ). Trajectory time elapsed between each position is 4 ps.

During MD simulation, 2000 atoms are released for realizing three deposition sets with the same compositions as in previous section. These sets of calculation are equivalent to releasing 70000 atoms on the previous larger surface $\left(100 \times 100 \AA^{2}\right)$, so it is equivalent to observing the film at a deposition time approximately seven times larger. Table 9 gives the real composition of HEA thin film in the experiments, the number of atoms really living in the simulated films and its composition.

Table 9: Simulated deposited alloy composition in the small size cell

\begin{tabular}{|c|c|c|c|c|c|c|}
\hline Atoms & $\mathrm{Al}$ & Co & $\mathrm{Cr}$ & $\mathrm{Cu}$ & $\mathrm{Fe}$ & $\mathrm{Ni}$ \\
\hline Sample 1 & \multicolumn{6}{|c|}{$\mathrm{Al}_{2} \mathrm{Co}_{9} \mathrm{Cr}_{32} \mathrm{Cu}_{39} \mathrm{Fe}_{12} \mathrm{Ni}_{6}(1660 / 2000)$} \\
\hline Deposited number & 37 & 165 & 523 & 643 & 189 & 103 \\
\hline Simulation composition & $2,2 \%$ & $9,9 \%$ & $31,5 \%$ & $38,7 \%$ & $11,4 \%$ & $6,2 \%$ \\
\hline Targeted composition & $2 \%$ & $9 \%$ & $32 \%$ & $39 \%$ & $11 \%$ & $6 \%$ \\
\hline Sample 2 & \multicolumn{6}{|c|}{$\mathrm{Al}_{3} \mathrm{Co}_{26} \mathrm{Cr}_{15} \mathrm{Cu}_{18} \mathrm{Fe}_{20} \mathrm{Ni}_{18}(1670 / 2000)$} \\
\hline Deposited number & 59 & 456 & 250 & 282 & 313 & 310 \\
\hline
\end{tabular}




\begin{tabular}{|c|c|c|c|c|c|c|}
\hline Simulation composition & $3,5 \%$ & $27,3 \%$ & $15,0 \%$ & $16,9 \%$ & $18,7 \%$ & $18,6 \%$ \\
\hline Targeted composition & $3 \%$ & $26 \%$ & $15 \%$ & $18 \%$ & $20 \%$ & $18 \%$ \\
\hline Sample 3 & \multicolumn{6}{|c|}{$\mathrm{Al}_{39} \mathrm{Co}_{10} \mathrm{Cr}_{14} \mathrm{Cu}_{18} \mathrm{Fe}_{13} \mathrm{Ni}_{6}(1656 / 2000)$} \\
\hline Deposited number & 634 & 186 & 218 & 305 & 208 & 105 \\
\hline Simulation composition & $38,3 \%$ & $11,2 \%$ & $13,2 \%$ & $18,4 \%$ & $12,6 \%$ & $6,3 \%$ \\
\hline Targeted composition & $39 \%$ & $10 \%$ & $14 \%$ & $18 \%$ & $13 \%$ & $6 \%$ \\
\hline
\end{tabular}

The films grew to approximately $10 \mathrm{~nm}$. Snapshots of the films with three different compositions deposited on $\mathrm{Si}(100)$ are presented in Figure 19. It can be clearly seen that a crystalline structure is formed in sample 1 and sample 2, above an amorphous HEA layer. While for sample 3, an amorphous structure is formed on the overall thickness.

Actually, throughout the process of atom deposition, there exist a competition between the dense packing (for lowering enthalpy) and the randomness of atoms (for increasing the configurational entropy) driven by thermal energy. In each step during simulation, each jumping atom or in-situ shaking is to seek its minimum-energy position under the rule of minimizing energy. But, at the same time, the kinetic energy or momentum also drives atoms to jump, which is against the tendency towards the minimum energy. With the same simulation conditions, the "engine" of this competition, enthalpy and entropy, is determined by the only varied parameter, the composition of the HEA. In sample 1 and 2, the dense packing becomes dominant in making the atomic configuration more ordered: this occurs for low Al content (2 and 3\%). In contrast, sample 3 a disordered or amorphous phase tends to stabilize: this occurs for large Al content (39\%). This can be interpreted as the highentropy effect. 

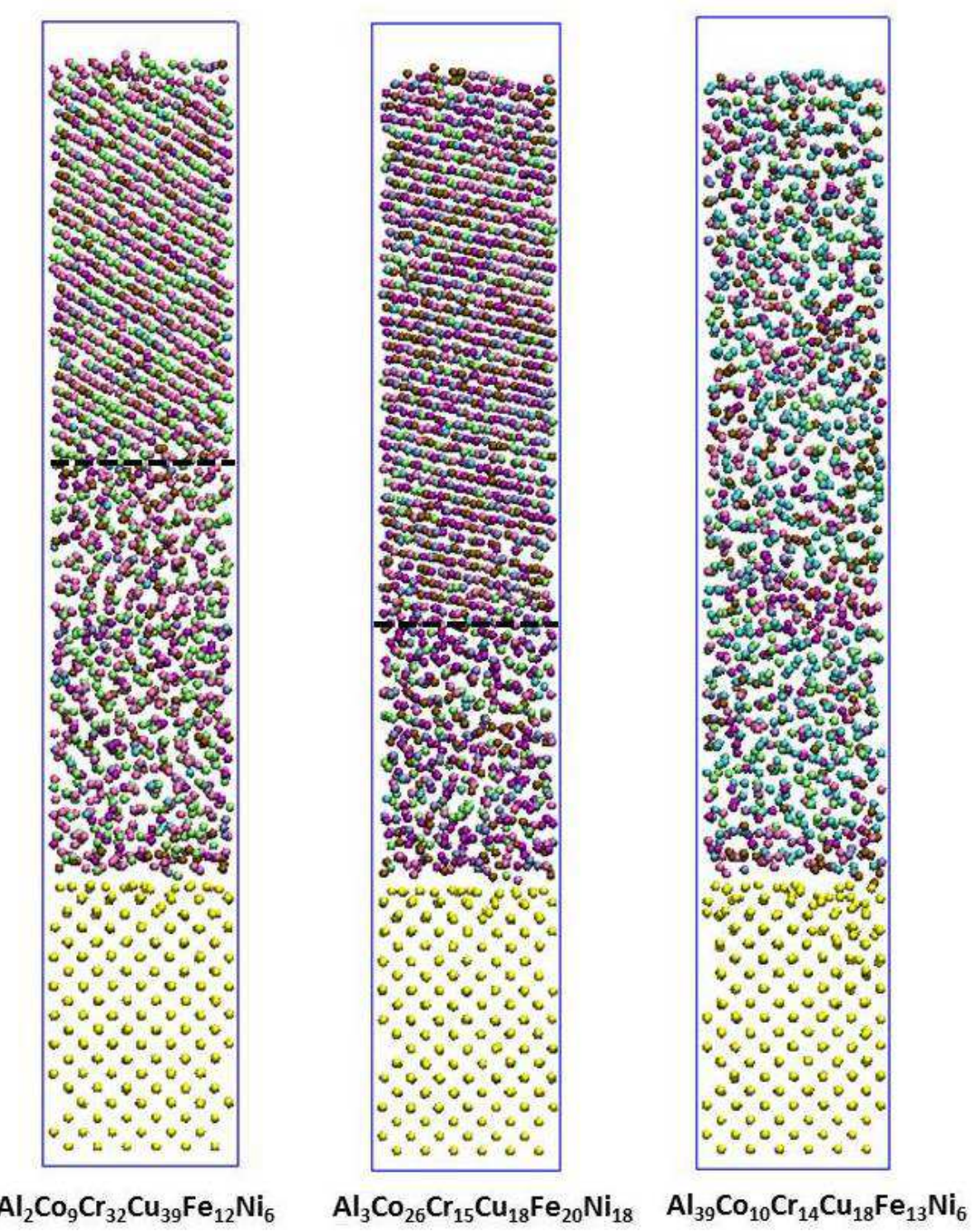

Figure 19: Snapshots of HEA films deposited on $\mathrm{Si}(100)$ substrate with small substrate, the dashed line separates the crystalline and amorphous structures. $\bullet \mathrm{Al}, \bullet \mathrm{Co}, \bullet \mathrm{Cr}, \bullet \mathrm{Cu}, \bullet \mathrm{Fe}, \bullet \mathrm{Ni}, \bullet \mathrm{Si}$

Figure 20 shows the RDF of the three samples and table 10 gives the 4 simulated neighbour distances and the corresponding theoretical crystal average values. In these three samples, the disappearance of the second neighbour distance comes from the disordered arrangement of the atoms preventing stacking order to grow. In sample 1 and 2, the RDFs show outstanding peaks that can be attributed to a crystalline structure, in agreement with the results presented in Figure 19. In sample 3, it is shown that the intensity of RDF is lower. Moreover, the first and second peaks become broad and fade away quickly. All of this depicts that sample 3 exhibits a low ordered structure. This is also in agreement 
with the snapshot of sample 3 in Figure 19. From a comparison among RDF patterns in Figure 20 versus Figure 14, it is seen that, as the continuous film grows, the RDF patterns change very little for alloys of sample 3 showing amorphous state but significantly for sample 1 and 2. For the continuous film the first fourth peaks becomes clearer and narrower and the fifth peak around $7.36 \AA$ arises, showing the crystal-like structure formed.

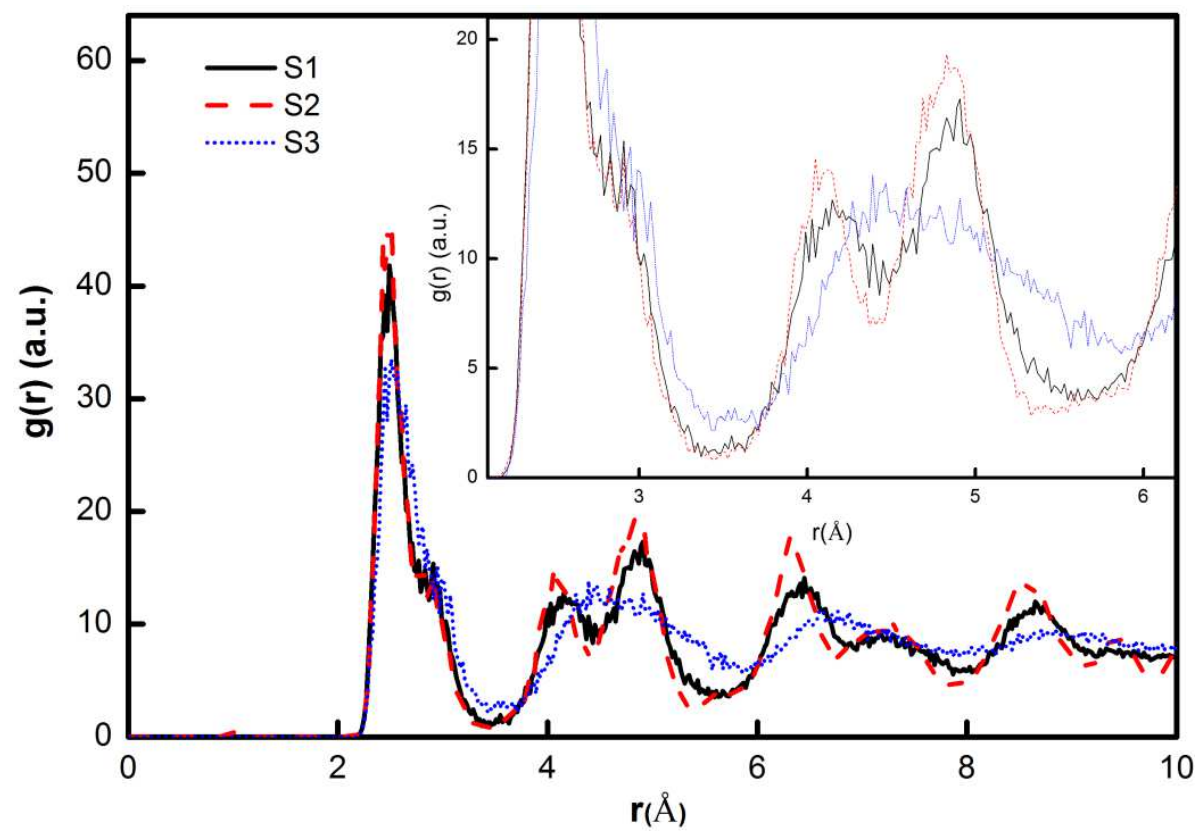

Figure 20: Total RDF of the HEA deposits at the different compositions of figure 21

Table 10: Average neighbour distances in the HEA compared to element crystal values.

\begin{tabular}{|l|c|c|c|c|}
\hline \multicolumn{1}{|c|}{ Elements } & $\begin{array}{c}1^{\text {st }} \text { neighbor } \\
(\AA)\end{array}$ & $\begin{array}{c}2^{\text {nd }} \text { neighbor } \\
(\AA)\end{array}$ & $\begin{array}{c}3^{\text {rd }} \text { neighbor } \\
(\AA)\end{array}$ & $\begin{array}{c}4^{\text {th }} \text { neighbor } \\
(\AA)\end{array}$ \\
\hline $\mathrm{Al}_{2} \mathrm{Co}_{9} \mathrm{Cr}_{32} \mathrm{Cu}_{39} \mathrm{Fe}_{12} \mathrm{Ni}_{6}$ (average) & 2.52 & 3.19 & 4.32 & 4.99 \\
\hline Sample1 & 2.48 & - & 4.08 & 4.83 \\
\hline $\mathrm{Al}_{3} \mathrm{Co}_{26} \mathrm{Cr}_{15} \mathrm{Cu}_{18} \mathrm{Fe}_{20} \mathrm{Ni}_{18}$ (average) & 2.52 & 3.19 & 4.19 & 5.14 \\
\hline $\mathrm{Sample}$ & 2.49 & - & 4.15 & 4.88 \\
\hline $\mathrm{Al}_{39} \mathrm{Co}_{10} \mathrm{Cr}_{14} \mathrm{Cu}_{18} \mathrm{Fe}_{13} \mathrm{Ni}_{6}$ (average) & 2.64 & 3.49 & 4.48 & 5.3 \\
\hline $\mathrm{Sample}$ & 2.52 & - & 4.42 & - \\
\hline
\end{tabular}


Figure 21 shows the intensity of the calculated X-ray intensities vs. 2- $\theta$ of HEA samples. The number of atom in this set of simulation is low, thus it is hard to get XRD pattern corresponding to the experiment. To circumvent this, we have repeated 25 times the original HEA, according to the periodic boundary condition in $\mathrm{x}$ and $\mathrm{y}$ direction. A system with around 50000 atoms was built for calculating more precisely the XRD patterns. The peak positions are shown in Table 11.

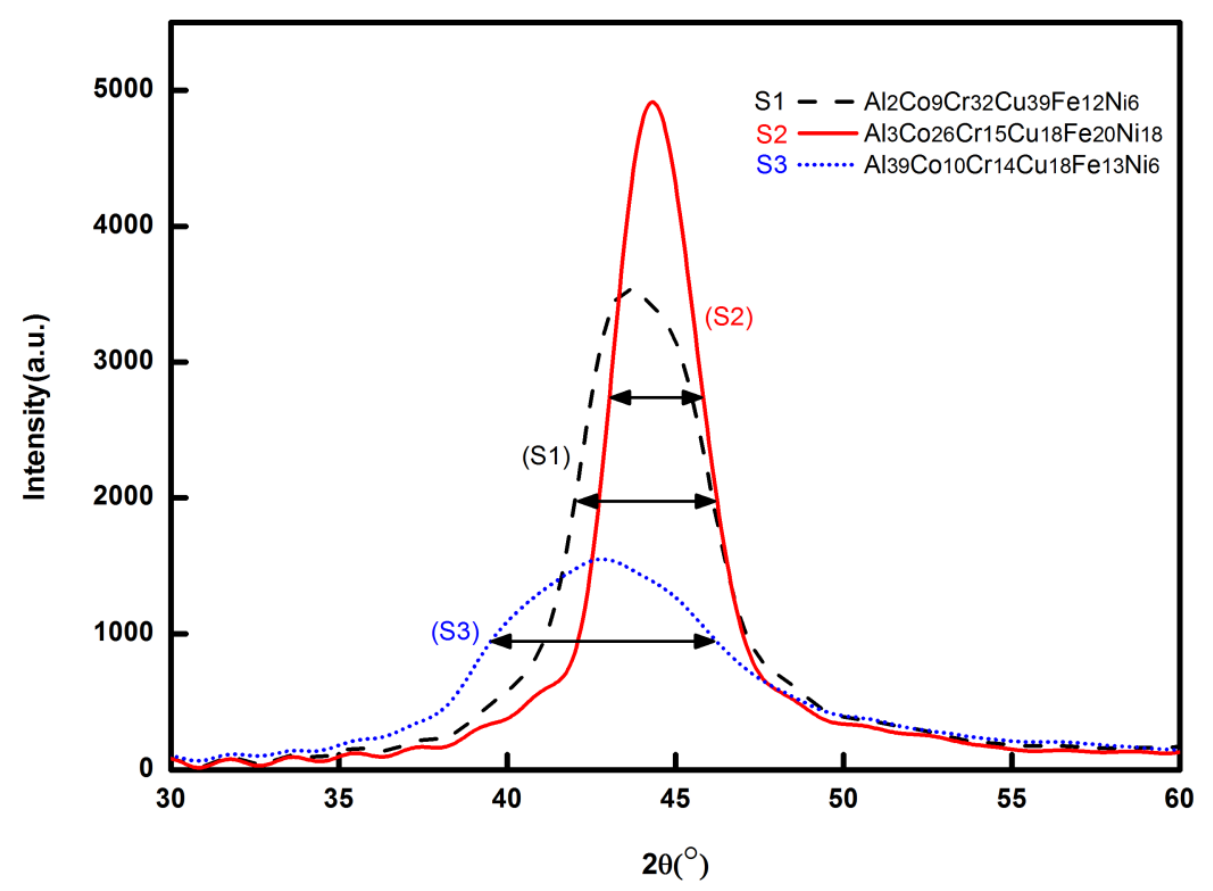

Figure 21: The simulated XRD patterns at different compositions.

Table 11: $2 \theta$ position of main XRD peak for HEA alloy in the experiment and simulation

Experiment

Unit: $2 \theta\left(^{\circ}\right)$

\begin{tabular}{|c|c|c|c|}
\hline HEA & $\mathrm{Al}_{2} \mathrm{Co}_{9} \mathrm{Cr}_{32} \mathrm{Cu}_{39} \mathrm{Fe}_{12} \mathrm{Ni}_{6}$ & $\mathrm{Al}_{3} \mathrm{Co}_{26} \mathrm{Cr}_{15} \mathrm{Cu}_{18} \mathrm{Fe}_{20} \mathrm{Ni}_{18}$ & $\mathrm{Al}_{39} \mathrm{Co}_{10} \mathrm{Cr}_{14} \mathrm{Cu}_{18} \mathrm{Fe}_{13} \mathrm{Ni}_{6}$ \\
\hline main peak & 43,81 & 44,41 & 43,77 \\
\hline
\end{tabular}

Simulation

Unit: $2 \theta\left(^{\circ}\right)$

\begin{tabular}{|c|c|c|c|}
\hline HEA & $\mathrm{Al}_{2} \mathrm{Co}_{9} \mathrm{Cr}_{32} \mathrm{Cu}_{39} \mathrm{Fe}_{12} \mathrm{Ni}_{6}$ & $\mathrm{Al}_{3} \mathrm{Co}_{26} \mathrm{Cr}_{15} \mathrm{Cu}_{18} \mathrm{Fe}_{20} \mathrm{Ni}_{18}$ & $\mathrm{Al}_{39} \mathrm{Co}_{10} \mathrm{Cr}_{14} \mathrm{Cu}_{18} \mathrm{Fe}_{13} \mathrm{Ni}_{6}$ \\
\hline main peak & 43.6 & 44.3 & 42.85 \\
\hline
\end{tabular}

The simulated peaks at position $2 \theta=42.85^{\circ}, 43.6^{\circ}$ and $44.3^{\circ}$ correspond to sample S3, S1 and S2, respectively. The S2 being close to the bcc(110) $\alpha$ structure while the S3 peak is rather consistent with 
$\mathrm{fcc}(111) \beta(\mathrm{Xie}, 2013 \mathrm{~b})$. In this latter case, because the peak is broader than for S1 and S2, the structure is much more short range order. These values are close to the experiment, with a small shift towards smaller angles, which may be caused by the limited size of the simulation box. Besides, with the same number of the deposited atoms, as already noticed, the XRD peak of sample 3 is broader than the others. This is consistent to the disordered structure shown in Figure 19. On the contrary, sample 1, 2 have thin and narrow peaks and the well crystallized structure arises with thickness around $4 \mathrm{~nm}$ and 5 $\mathrm{nm}$ respectively in Figure 19. The width of the simulated XRD peak is proportional to the "amorphous" or crystallized phase in the simulation. Nevertheless, in experiments (Figure 16) S2 displays the broader peak, while in the present simulations it is S3. This discrepancy is not well explained. Due to limited number of atoms in the simulation compared to experiment, the comparison can only be qualitative. One has to keep in mind that the other atoms in the expanded film are just the duplication of the same unit cell. This is the limitation of this model. Nevertheless, we can use this procedure to get some information about the crystalline or amorphous nature of the films, depending on the composition of the HEA and to compare with the experiment. What is interesting in using small cells is thus to study the structure for larger thicknesses.

\section{Conclusion}

Maturity of semi-empirical analytic interaction potential determination allows extensive (parallel) implementation of classical MD simulations for handling complex systems among them thin films growth phenomena. Plasma sputtering deposition being a widely use technology, predicting structures, morphologies and properties at atomic scales is challenging for factory of the future, where integrating computational materials science will help in saving costly experimental tests. Especially the initial steps of growth driving the final microstructure are reachable by MD simulation provided the deposition conditions can be translated as inputs for MD simulations. The energetic of the deposition, i.e. how to correctly describe the energy dissipation through the substrate, can be handled with adhoc velocity rescaling, provided relaxation times are known. The definitive unreachable information is the deposition rate due to the unphysical large incoming particle fluxes compared to sputtering experiments. The present work and the numerous others previously published or being published, 
constantly demonstrate that the compositions, structure, morphologies and sometimes thin film properties are correctly described using MD simulations.

Cases studies proposed here should be seen as highlighting how MD is able to predict or to be compared to experiments. First, $\mathrm{Zr}_{\mathrm{x}} \mathrm{Cu}_{100-\mathrm{x}}$ thin film growth is studied by MD simulations using initial conditions consistent with magnetron co-sputtering process. The crystallinity of the films was analyzed by calculated RDFs and XRD patterns. The results show that films containing large amount of one of the element (higher than $80 \%$ ) are crystallized, whereas for intermediate compositions low ordered phase is evidenced. This trend is due to chemical disorder, since both atoms seem to be incorporated in the same lattice (solid solution) which induces distortion of the lattice parameter. Results also show that the morphology of the films is dependent on the mean kinetic energy of the incoming atoms. With higher depositing energy, a compact and uniform film is likely to form. When the kinetic energy of the atoms are above a threshold a top amorphous zone is growing, whereas at lower energy, the morphology is in the form of clusters or film depending on the atomic composition. The more crystalline $\mathrm{Zr}_{90} \mathrm{Cu}_{10}$ evolves from a polycrystalline state at low impinging kinetic energy to a pure crystalline one at larger.

Second, growth of complex systems such as HEA clusters or thin films can be studied by MD simulations. Due to short diffusion range, thin film growth has been studied on rather small simulation box while cluster growth was studied on larger simulation box. Thin film structures are shown to be sensitive to the HEA composition. Amorphous films with top crystalline layer are growing for low Al content (2 and 3\%). Pure amorphous thin film is observed for the composition with the largest $\mathrm{Al}$ content (39\%). Clusters remain always amorphous as RDFs display broad peaks. Tentative comparison with experimental XRD patterns is limited to the agreement of the peak positions. Unfortunately no comparison with the peak intensity is possible due to a too high experimental thickness. Certainly comparison between MD simulations and ultra-thin deposited layer would be more fruitful, provided XRD $\theta-2 \theta$ measurements can be possible with a very low film thickness (around 10nm).

\section{Acknowledgements}

China Scolarship Council is gratefully acknowledged for grant \#2009 60212. 


\section{References}

J. Alami, S. Bolz, K. Sarakinos 2009 High power pulsed magnetron sputtering: Fundamentals and applications, Journal of Alloys and Compounds 483, 530-534

B. Alder, T. Wainwright, 1957 Phase transition for a hard sphere system, The Journal of Chemical Physics, 27 1208-1209.

B. Alder, T. Wainwright, 1958 Transport processes in statistical mechanics, Ed. I. Prigogine, Interscience Publishers, New York) pp. 97-131

B.J. Alder and T.E. Wainwright 1959 Studies in Molecular Dynamics. I. General Method, J. Chem. Phys., 31(2), 459- 466.

M.P. Allen and D.J. Tildesley, 1987. Computer Simulations of Liquids, New York: Oxford University Press.

Almyras, C.E. Lekka, N. Mattern, G.A. Evangelakis, 2010 On the microstructure of the $\mathrm{Cu}_{65} \mathrm{Zr}_{35}$ and $\mathrm{Cu}_{35} \mathrm{Zr}_{65}$ metallic glasses, Scripta Materialia 62 33-36.

Baguer N, Georgieva V, Calderin L, Todorov I T, VanGils S, Bogaerts A, 2009 Study of the nucleation and growth of $\mathrm{TiO} 2$ and $\mathrm{ZnO}$ thin films by means of molecular dynamics simulations $J$. Crystal Growth 311 4034-4043

H.J.C. Berendsen, J.P.M. Postma, W.F. van Gunsteren, A. DiNola, and H.R. Haak, 1984. Molecular dynamics with coupling to an external bath, J. Chem. Phys., 81, 3684-3690.

Blackwell S, Smith R, Kenny S D, Walls J M, 2012 Modeling evaporation, ion-beam assist, and magnetron sputtering of thin metal films over realistic time scales Phys. Rev. B 86035416

A Bogaerts, E Bultinck, M Eckert, V Georgieva, M Mao, E Neyts, L Schwaederle 2009 Computer Modeling of Plasmas and Plasma-Surface Interactions, Plasma Process. Polym. 6, 295-307

A Bogaerts, C De Bie, M Eckert, V Georgieva, T Martens, E Neyts, and S Tinck

Modeling of the plasma chemistry and plasma-surface interactions in reactive plasmas 2010 Pure Appl. Chem. 821283-1299

A Bogaerts, R Aerts, R Snoeckx, W Somers, W Van Gaens, M Yusupov and E Neyts 2012, Modeling of plasma and plasma-surface interactions for medical, environmental and nano applications, Journal of Physics: Conference Series 399012011

P Brault 2011 Plasma deposition of catalytic thin films: Experiments, applications, molecular modeling, Surface \& Coatings Technology 205 S15-S23

P. Brault, A. Caillard, C. Charles, R. Boswell, D. B. Graves 2012, Platinum nanocluster growth on vertically aligned carbon nanofiber arrays: sputtering experiments and molecular dynamics simulations, Appl. Surf. Sci. 263 352-356

D. W. Brenner, 1990. Empirical potential for hydrocarbons for use in simulating the chemical vapor deposition of diamond films, Phys. Rev. B 42, 9458.

D. Brenner, 2000 The art and science of an analytical potential, Physica Status Solidi (b) 217, 23

H.-W. Chang, P.-K. Huang, J.-W. Yeh, A. Davison, C.-H. Tsau, C.-C. Yang, 2008 Influence of substrate bias, deposition temperature and post-deposition annealing on the structure and properties of 
multi-principal-component (AlCrMoSiTi) N coatings, Surface and Coatings Technology, 202 33603366

T.K. Chen, T.T. Shun, J.W. Yeh, M.S. Wong, 2004 Nanostructured nitride films of multi-element high-entropy alloys by reactive DC sputtering, Surface and Coatings Technology 188-189 193-200

T.-K. Chen, M.-S. Wong, T.-T. Shun, J.-W. Yeh, 2005 Nanostructured nitride films of multi-element high-entropy alloys by reactive DC sputtering, Surface and Coatings Technology 200 1361-1365.

Y.Q. Cheng, E. Ma, 2011Atomic-level structure and structure-property relationship in metallic glasses, Progress In Materials Science 56 379-473

F. Cleri, V. Rosato, 1993 Tight-binding potentials for transition metals and alloys, Phys. Rev. B 48, 22.

D. G. Coronell, D. E. Hansen, A. F. Voter, C-L Liu, X-Y Liu, and J D. Kress, 1998 Molecular dynamics-based ion-surface interaction models for ionized physical vapor deposition feature scale simulations, Applied Physics Letters 73, 3860

J. Das, M.B. Tang, K.B. Kim, R. Theissmann, F. Baier, W.H. Wang, J. Eckert, 2005 "WorkHardenable" Ductile Bulk Metallic Glass, Physical Review Letters, 94205501.

M. S. Daw, M. I. Baskes, 1983. Semiempirical, Quantum Mechanical Calculation of Hydrogen Embrittlement in Metals, Phys. Rev. Lett. 50, 1285.

M. S. Daw, M. I. Baskes, 1984. Embedded-atom method: Derivation and application to impurities, surfaces, and other defects in metals, Phys. Rev. B 296443.

M. S. Daw, S. M. Foiles, M. I. Baskes,1993. The embedded-atom method: a review of theory and applications, Mat. Sci. Reports 9, 251-310.

D. Depla, W.P. Leroy, 2012 Magnetron sputter deposition as visualized by Monte Carlo modeling, Thin Solid Films $\mathbf{5 2 0} 6337$

V. Dolique, A.-L. Thomann, P. Brault, Y. Tessier, P. Gillon, 2009 Complex structure/composition relationship in thin films of AlCoCrCuFeNi high entropy alloy, Materials Chemistry And Physics 117 142-147.

V. Dolique, A.-L. Thomann, P. Brault, Y. Tessier, P. Gillon, 2010 Thermal stability of AlCoCrCuFeNi high entropy alloy thin films studied by in-situ XRD analysis, Surface and Coatings Technology 204 1989-1992.

J. Dudonis, R. Bručas, A. Miniotas, 1996 Synthesis of amorphous $\mathrm{Zr}-\mathrm{Cu}$ alloys by magnetron cosputtering, Thin Solid Films, 275 164-167.

M. W. Finnis, J. E. Sinclair, 1984. A simple empirical N-body potential for transition metals, Philos. Mag. A 50, 45-55.

S. M. Foiles 1985 Application of the embedded-atom method to liquid transition metals, Physical Review B, 323409.

S.M. Foiles, M.I. Baskes 2012 Contributions of the embedded-atom method to materials science and engineering, MRS Bulletin, 37 485-491.

S. M. Foiles, M. I. Baskes, M. S. Daw, 1986. Embedded-atom-method functions for the fcc metals 
$\mathrm{Cu}, \mathrm{Ag}, \mathrm{Au}, \mathrm{Ni}, \mathrm{Pd}, \mathrm{Pt}$, and their alloys, Phys. Rev. B 33, 7983-799; Erratum: Phys. Rev. B 37, 10378, 1988.

D. Frenkel and B. Smit, 2001. Understanding Molecular Simulation, Orlando: Academic Press. L. A. Girifalco, V. G. Weizer, 1959. Application of the Morse potential function to cubic metals, Phys. Rev. 114, 687.

V Georgieva, I T. Todorov, A Bogaerts, 2010 Molecular dynamics simulation of oxide thin film growth: Importance of the inter-atomic interaction potential, Chemical Physics Letters 485 315-319

V Georgieva, A F. Voter, and A Bogaerts, 2011 Understanding the Surface Diffusion Processes during Magnetron Sputter-Deposition of Complex Oxide Mg-Al-O Thin Films, Cryst. Growth Des. 11, 2553-2558

F. Gou, A.W. Kleyn, and M.A. Gleeson, 2008. The application of molecular dynamics to the study of plasma-surface interactions: $\mathrm{CF}_{\mathrm{x}}$ with silicon, International Reviews in Physical Chemistry 27, 229 271.

C. Goyhenex, H. Bulou, 2001. Theoretical insight in the energetics of Co adsorption on a reconstructed $\mathrm{Au}(111)$ substrate, Phys. Rev. B63 235404.

A. Gras-Marti, J.A. Valles-Abarca, 1983 Slowing down and thermalization of sputtered particle fluxes: Energy distributions, Journal of Applied Physics, 54 1071-1075

D.B. Graves and C.F. Abrams, 2001. Molecular Dynamics Simulations of Ion-Surface Interactions with Applications to Plasma Processing, Adv. Chem. Eng., Ed. A. Chakraborty, vol. 28, Academic Press.

D B Graves and P Brault 2009 Molecular dynamics for low temperature plasma-surface interaction studies, J. Phys. D: Appl. Phys. 42194011 (27pp)

X.-Y. Guo, P. Brault, 2001. Early stages of silicon nitride film growth studied by molecular dynamics simulations, Surf. Sci. 488, 133-140.

J.M. Haile, 1992. Molecular Dynamics Simulations, New York: John Wiley and Sons.

U. Hansen, S. Rodgers and K. F. Jensen 2000 Modeling of metal thin film growth: Linking angstromscale molecular dynamics results to micron-scale film topographies, Phys. Rev. B 62 2869-2878

U Helmersson, M Lattemann, J Bohlmark, A P Ehiasarian, JT Gudmundsson 2006 Ionized physical vapor deposition (IPVD): A review of technology and applications, Thin Solid Films 513 1-24

Q. Hou, M. Hou, L. Bardotti, B. Prevel, P. Melinon, A. Perez, 2000. Deposition of AuN clusters on $\mathrm{Au}(111)$ surfaces: I. Atomic-scale modelling, Phys. Rev. B 62, 2825.

U. Hsu, U. Hung, J. Yeh, S. Chen, Y. Huang, C. Yang, 2007 Alloying behavior of iron, gold and silver in AlCoCrCuNi-based equimolar high-entropy alloys, Materials Science and Engineering: A $460 \quad 403-408$

R. Iftimie, P. Minary, and M.E. Tuckerman, 2005. Ab initio molecular dynamics: Concepts, recent developments and future trends, PNAS, 102(19), 6654-6659.

H U Jäger and A Yu Belov, 2003 ta-C deposition simulations: Film properties and times-resolved dynamics of film formation, Phys. Rev. B, 68024201. 
S.-W. Kao, J.-W. Yeh, T.-S. Chin, 2008 Rapidly solidified structure of alloys with up to eight equalmolar elements - a simulation by molecular dynamics, Journal of Physics: Condensed Matter, 20 145214.

N. Karpe, J. Bøttiger, J.P. Krog, A. Nordström, Ö. Rapp, 1996 Influence of deposition conditions and ion irradiation on thin films of amorphous $\mathrm{Cu}-\mathrm{Zr}$ superconductors, Thin Solid Films, 275 82-86

Y. Kawamura, H. Kato, A. Inoue, T. Masumoto, 1997 Fabrication of bulk amorphous alloys by powder consolidation, International Journal of Powder Metallurgy, 33 50-61

Y. Li, S.J. Poon, G.J. Shiflet, J. Xu, D.H. Kim, and J.F. Löffler 2007 Formation of Bulk Metallic Glasses and Their Composites, MRS Bulletin 32624

C.-M. Lin, H.-L. Tsai, 2011 Evolution of microstructure, hardness, and corrosion properties of highentropy A10.5CoCrFeNi alloy, Intermetallics 19 288-294

Z.-B. Lin, R. -A. Johnson, and L.-V. Zhigilei, 2008 Computational study of the generation of crystal defects in a bec metal target irradiated by short laser pulses, Physical Review B 77, 214108

Maizuradze GG, Thomson D L, Wagner A F 2003 Interpolating Moving Least Squares Method s for Fitting Potential Energy Surfaces: Detailed Analysis of One-Dimensional Applications, J. Chem. Phys. 119, 10002

T. Masumoto 1994 Recent progress of amorphous metallic materials, Sci. Rep. RITU A39 91-102.

T. Mei-Bo, Z. De-Qian, P. Ming-Xiang, W. Wei-Hua, 2004 Binary $\mathrm{Cu}-\mathrm{Zr}$ bulk metallic glasses, Chinese Physics Letters, 21901

K. Meyer, I.K. Schuller, C.M. Falco, 1981 Thermalization of sputtered atoms, Journal of Applied Physics, 52 5803-5805.

J. Musil, R. Daniel, 2003 Structure and mechanical properties of magnetron sputtered $\mathrm{Zr}-\mathrm{Ti}-\mathrm{Cu}-\mathrm{N}$ films, Surface and Coatings Technology, 166 243-253

J. Musil, P. Baroch, J. Vlck, K.H. Nam, J.G. Han 2005 Reactive magnetron sputtering of thin films: present status and trends, Thin Solid Films 475 208-218

E. C. Neyts, A. Bogaerts 2013, Combining molecular dynamics with Monte Carlo simulations: implementations and applications, Theor Chem Acc 1321320

E. Neyts, U. Khalilov, G. Pourtois, A. C. T. van Duin, 2012 Hyperthermal Oxidation of $\mathrm{Si}(100) 2 \mathrm{x} 1$ Surfaces: Effect of Growth Temperature, J. Phys. Chem. C 116, 8649-8656

B Ni, S B. Sinnott, P T. Mikulski, and J A. Harrison 2002 Compression of Carbon Nanotubes Filled with C60, CH4, or Ne: Predictions from Molecular Dynamics Simulations, Phys. Rev. Lett. 88 205505

K. D. Nielson, A. C. T. van Duin, J. Oxgaard, W.-Q. Deng, W. A. Goddard, 2005 Development of the ReaxFF Reactive Force Field for Describing Transition Metal Catalyzed Reactions, with Application to the Initial Stages of the Catalytic Formation of Carbon Nanotubes. The Journal of Physical

Chemistry A 109 493-499.

A. Nikitin, H. Ogasawara, D. Mann, R. Deneck, Z. Zhang, H. Dai, K. Cho, and A. Nilsson 2005 Hydrogenation of Single-Walled Carbon Nanotubes, Phys. Rev. Lett. 95, 225507 
A. Păduraru, A. Kenoufi, N.P. Bailey, J. Schiøtz, 2007 An interatomic potential for studying CuZr bulk metallic glasses, Advanced Engineering Materials, 9 505-508

S. J. Plimpton, 1995 Fast Parallel Algorithms for Short-Range Molecular Dynamics, J. Comp. Phys. 117 1-19; http://lammps.sandia.gov

S. J. Plimpton and A. P. Thompson 2012 Computational aspects of many-body potentials, MRS Bulletin 37 513-521

W A Press, S A Teukolsky, W T Vetterling B P Flannery 1992 Numerical recipes $\left(2^{\text {nd }}\right.$ edition Cambridge University Press, Cambridge)

D.C. Rapaport, 1995. The Art of Molecular Dynamics Simulations, Cambridge: Cambridge University Press.

V. Rosato, M. Guillope, B. Legrand, 1989. Thermodynamical and structural properties of fcc transition metals using a simple tight-binding model, Philos. Mag. A 59, 321-336.

K. Sarakinos, J. Alami, S. Konstantinidis 2010 High power pulsed magnetron sputtering: A review on scientific and engineering state of the art, Surface \& Coatings Technology 204 1661-1684

Z. Sha, Y. Feng, Y. Li, 2010 Statistical composition-structure-property correlation and glass-forming ability based on the full icosahedra in $\mathrm{Cu}-\mathrm{Zr}$ metallic glasses, Applied Physics Letters, 96061903

Z.D. Sha, Y.W. Zhang, Y.P. Feng, Y. Li, 2011 Molecular dynamics studies of short to medium range order in Cu64Zr36 metallic glass, Journal of Alloys And Compounds, 509 8319-8322.

S. J. Stuart, A. B. Tutein, J. A. Harrison2, 2000 A reactive potential for hydrocarbons with intermolecular interactions, J. Chem. Phys. 112, 6472

A. P. Sutton, J. Chen, 1990. Long-range Finnis-Sinclair potentials, Philos. Mag. Lett. 61139.

W. C. Swope, H. C. Andersen, P. H. Berens, K. R. Wilson, 1982. A Computer Simulation Method for the Calculation of Equilibrium Constants for the Formation of Physical Clusters of Molecules: Application to Small Water Clusters, J. Chem. Phys. 76, 637.

J. Tersoff, 1988a. New empirical approach for the structure and energy of covalent systems, Phys. Rev. B 376991 .

J. Tersoff, 1988b Empirical interatomic potential for silicon with improved elastic properties, Physical Review B, 38 9902-9905.

J. Tersoff, 1989. Modeling solid-state chemistry: Interatomic potentials for multicomponent systems, Phys. Rev. B 39 5566, see also Erratum: Phys. Rev. B 41, 3248 - 3248 (1990)

G. Treglia, B. Legrand, F. Ducastelle, A. Saul, C. Gallis, I. Meunier, C. Mottet, A. Senhaji, 1999. Alloy surfaces: segregation, reconstruction and phase transitions, Comp. Mat. Sci. 15, 196-235

M.-H. Tsai, J.-W. Yeh, J.-Y. Gan, 2008 Diffusion barrier properties of AlMoNbSiTaTiVZr highentropy alloy layer between copper and silicon, Thin Solid Films $\mathbf{5 1 6} 5527-5530$

A. C. T. van Duin, S. Dasgupta, F. Lorant, W. A. Goddard, 2001 ReaxFF: A Reactive Force Field for Hydrocarbons, The Journal of Physical Chemistry A 105 9396-9409

K. Van Aeken, S. Mahieu, D. Depla 2008 The metal flux from a rotating cylindrical magnetron : a 
Monte Carlo simulation, Journal of Physics D.: Applied Physics 4120530

Wadley H N G, Zhou X, R A Johnson, Neurock M, 2001 Mechanisms, models and methods of vapour deposition, Progress in Materials Science 46 329-377

D. Wang, Y. Li, B. Sun, M. Sui, K. Lu, E. Ma, 2004 Bulk metallic glass formation in the binary CuZr system, Applied Physics Letters, 84 4029-4031

J.-M. Wu, S.-J. Lin, J.-W. Yeh, S.-K. Chen, Y.-S. Huang, H.-C. Chen, 2006 Adhesive wear behavior of $\mathrm{AlxCoCrCuFeNi}$ high-entropy alloys as a function of aluminum content, Wear 261 513-519

L. Xie, P. Brault, A.-L. Thomann, L. Bedra 2013a Molecular dynamics simulation of binary $\mathrm{Zr}_{\mathrm{x}} \mathrm{Cu}_{100-}$ x metallic glass thin film growth, Appl. Surf. Sci. $274164-170$

L. Xie, P. Brault, A.-L. Thomann, J.-M. Bauchire, 2013b AlCoCrCuFeNi high entropy alloy cluster growth and annealing on silicon: A classical molecular dynamics simulation study, Appl. Surf. Sci.

285P $810-816$

D. Xu, B. Lohwongwatana, G. Duan, W. Johnson, C. Garland, 2004 Bulk metallic glass formation in binary $\mathrm{Cu}$-rich alloy series- $\mathrm{Cu}_{100-\mathrm{x}} \mathrm{Zr}_{\mathrm{x}}(\mathrm{x}=34,36,38.2,40$ at.\%) and mechanical properties of bulk $\mathrm{Cu}_{64} \mathrm{Zr}_{36}$ glass, Acta Materialia, 52 2621-2624

X. Yang, Y. Zhang, 2012 Prediction of high-entropy stabilized solid-solution in multi-component alloys, Materials Chemistry and Physics, 132 233-238

J Yeh, 2006 Recent progress in high-entropy alloys, Annales de chimie, 31 633-648.

J.W. Yeh, S.K. Chen, S.J. Lin, J.Y. Gan, T.S. Chin, T.T. Shun, C.H. Tsau, S.Y. Chang, 2004 Nanostructured High-Entropy Alloys with Multiple Principal Elements: Novel Alloy Design Concepts and Outcomes, Advanced Engineering Materials 6 299-303

P. Yu, H. Bai, W. Wang, 2006 Superior glass-forming ability of CuZr alloys from minor additions, Journal of Materials Research, 21 1674-1679.

L. Zhang, S. Jiang 2002 Molecular simulation study of nanoscale friction for alkyl monolayers on Si (111), The Journal of Chemical Physics 1171804

Y Zhang, T T Zuo, Z Tang, M C Gao, K A Dahmen, P K Liaw, Z P Lu 2014 Microstructures and properties of high-entropy alloys, Progress in Materials Science 61 1-93

S. Zhen, G.J. Davies 1983 Calculation of the Lennard-Jones n-m potential energy parameters for metals, physica status solidi (a) 78 595-605.

X. Zhou, H. Wadley, R.A. Johnson, D. Larson, N. Tabat, A. Cerezo, A. Petford-Long, G. Smith, P. Clifton, R. Martens 2001 Atomic scale structure of sputtered metal multilayers, Acta Materialia, 49 4005-4015.

X. Zhou, R. Johnson, H. Wadley 2004 Misfit-energy-increasing dislocations in vapor-deposited CoFe/NiFe multilayers, Physical Review B 69144113 